\title{
Plasma and Electric Field Boundaries at High and Low Altitudes on July 29, 1977
}

\author{
Prepared by \\ J. F. FENNELL \\ Space Sciences Laboratory \\ R. G. JOHNSON \\ Lockheed Palo Alto Research Laboratory \\ Palo Alto, Calif. \\ D. T. YOUNG \\ University of Bern \\ Bern, Switzerland \\ R. B. TORBERT \\ Unıversity of California \\ Berkeley, Calif. \\ T. E. MOORE \\ University of New Hampshire \\ Durham, New Hampshire
}

12 January 1982

Contract No. ATM-8000518

\section{Prepared for \\ NATIONAL SCIENCE FOUNDATION \\ Washington, D.C. 20550}

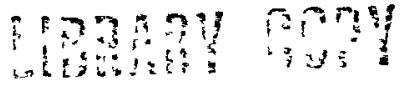

1.4, 992

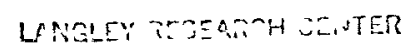

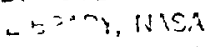

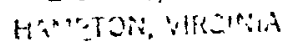

Laboratory Operations

THE AEROSPACE CORPORATION 


\section{LABORATORY OPERATIONS}

The Laboratory Operations of The Aerospace Corporation is conduct1ng experImental and theoretical investigations necessary for the evaluation and application of sclentific advances to new eflitary space systens. Versatility and flexibility have been developed to a high degree by the laboratory personnel in dealing with the wany problems encountered in the nation's rapidly developing space systems Expertise in the latest sclentific developaents is vital to the accomplishment of tasks related to these problems The laboratories that contribute to this research are

Aerophysics Laboratory Launch vehicle and reentry aerodynamics and heat transfer, propulsion chemistry and flutd mechanics, structural mechanics, flight dynanlcs, high-temperature therwomechanics, gas kinetics and radiation, research in environmental chemistry and contanination, $c w$ and pulsed chenical laser development including chemical kinetics, spectroscopy, optical resonators and beam pointing, atmospheric propagation, laser effects and countermeasures

Chemistry and Physics Laboratory Atmospheric chealcal reactions, atwospheric optics, light scattering, state-speciflc chealcal reactions and radiat10n transport in rocket plumes, applied laser spectroscopy, laser chenistry, battery electrochemistry, space vacuum and radiation effects on materials, lubrication and surface phenomena, themionic enlssion, photosenative materials and detectors, atoaic frequency standards, and bloenvironmental research and monitoring.

Electronics Research Laboratory Microelectronics, GaAs low-nolse and power devices, seniconductor lasers, electromagnetic and optical propagation phenomena, quantum electronics, laser communications, lidar, and electro-optics, communication sciences, applied electronics, seniconductor crystal and device physics, radiometric imaging, millimeter-wave and ulcrowave technology

Information Sclences Research Office. Progran verification, program translation, performance-sensitive system design, distributed architectures for saceborne conputers, fault-tolerant computer astems, artificial intelligence. and wicroelectronics applications

Materials Sclences Laboratory Development of new materials wetal matrix composites, polymers, and new forms of carbon, component fallure analysis and reliablity, fracture mechanics and stress corrosion, evaluation of materials in space environment, aaterials performance in space transportation systews, analysis of systems vulnerability and survivability in enemy-induced environments

Space Sclences Laboratory Atmospherlc and lonospheric physics, radiation frow the atsosphere, density and composition of the upper atmosphere, aurorae and airglow, magnetospheric physics, cosaic rays, generation and propagation of plasma waves in the magnetosphere, solar physics, Infrared astronomy, the effects of nuclear explosions, magnetic storms, and solar activity on the earth's atmosphere, lonosphere, and agnetosphere, the effects of optical, electromagnetic, and particulate radiations in space on space systems 
PLASMA AND ELECTRIC FIELD BOUNDARIES AT HIGH AND LOW ALTITUDES ON JULY 29, 1977

\author{
Prepared by \\ J. F. Fennell \\ Space Sciences Laboratory \\ R. G. Johnson \\ Lockheed Palo Alto Research Laboratory \\ Palo Alto, California \\ D. T. Young \\ University of Bern \\ Bern, Switzerland \\ R. B. Torbert \\ University of California \\ Berkeley, California \\ T. E. Moore \\ University of New Hampshire \\ Durham, New Hampshire
}

12 January 1982

THE AEROSPACE CORPORATION

E1 Segundo, California 90245

Contract No. ATM-8000518

Prepared for

NATIONAL SCIENCE FOUNDATION

Washington, D.C. 20550 
This Page Intentionally Left Blank 
PLASMA AND ELECTRIC FIELD BOUNDARIES

AT HIGH AND LOW ALTITUDES

ON JULY 29, 1977

Prepared by

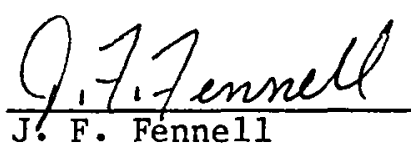

$\frac{\text { Y.t.7. for D.T. Young }}{\text { D. T. Young }}$

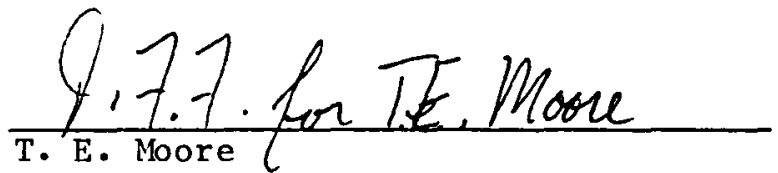

Approved by

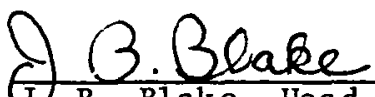

If B. Blake, Head

Space Particles and Fields Department
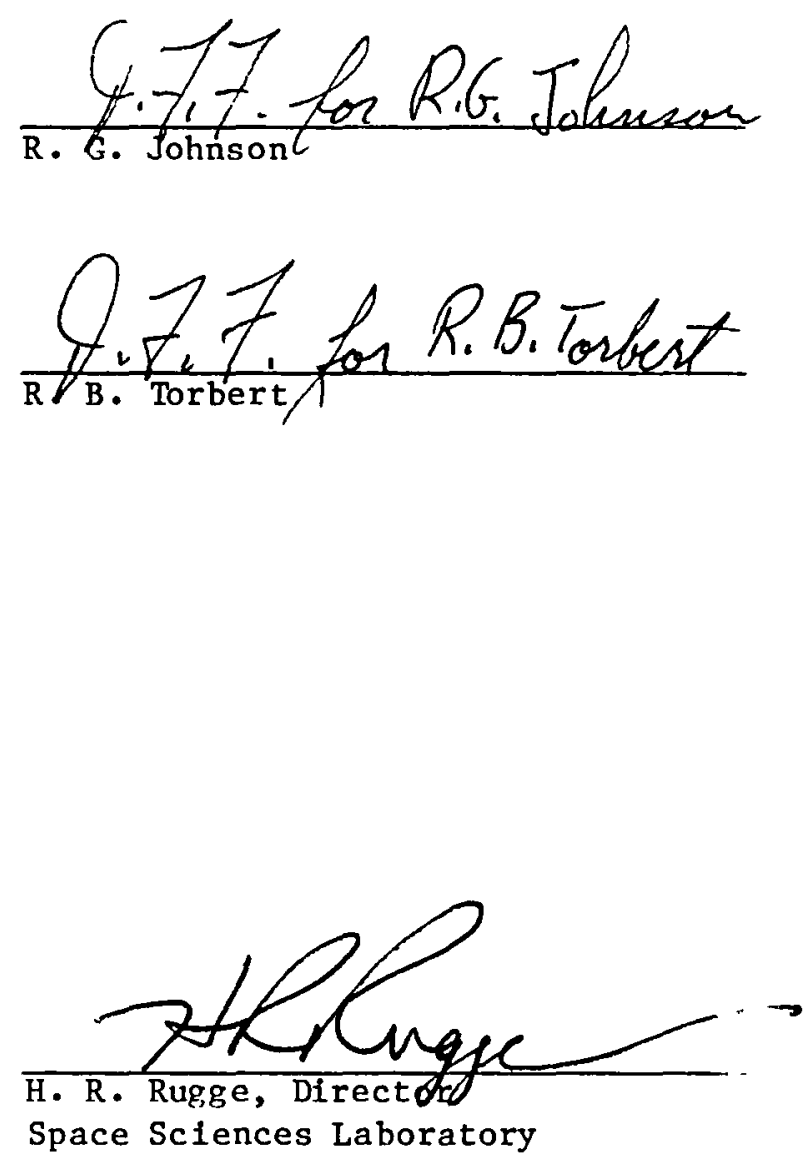
This Page Intentionally Left Blank 


\section{ABS TRAC T}

The Iils event of July 29, 1977 was the topic of a coordinated data analysis workshop in October 1979. During this workshop the hot plasma observations obtained by several spacecraft (GEOS-1, AIS-6, S3-3 and AE-C) both at high and low altitudes were compared. The high altitude data show that the magnetopause was compressed to between 6.6 and $7.0 \mathrm{R}$ near $13 \mathrm{MLT}$. The plasma ion composition measured, at high altitudes outside the plasmasphere, by GEOS-1 was seen to be primarily $0^{+}$. These heavy ions were also observed at Low altitudes outside the plasmasphere. Both GEOS-1 and S3-3 observations show that at times these ions were found well below the plasmapause inside the plasmasphere. Comparisons of the low altitude (S3-3) plasma and DC electric field data show that the outer limits of the plasmasphere was not always corotating at the low $L$ shells ( $L \lesssim 3$ ) on this disturbed day. The corotation boundary, the estimated plasmapause boundary and the boundary of the inner edge of plasma sheet ions were usually found to be at the same position. The inner edge of the plasma sheet electrons near dawn and dusk, plus the polar cap boundaries, were determined from the low altitude data. The inner edge of plasma sheet electrons was observed at higher latitudes ( $\mathrm{L}$ shells) than the plasmasphere boundary during disturbed times. This inner edge of the plastha sheet showed a strong dawn to dusk asymmetry. These inner edges of the plasma sheet ions and electrons were found to be in relatively good agreement with the predictions of the Rice Unfversity Convection Model (Wolf et al., 1981). The inner edge of the plasma sheet electrons was found to be in good agreement wlth inner edge of the $>80 \mathrm{keV}$ ring current ion precipitation. The $53-3$ data showed that, late on July 29 , the auroral precipitation extended above $\Lambda \sim 85.7^{\circ}$ on the nightside. At the same time the inner edge of the ring 
current and plasna sheet also moved to high latıtudes $\left(\Lambda \sim 72^{\circ}\right)$ reflecting an apparent inflation of the magnetosphere. 


\section{Acknowledgements}

We would like to thank $\mathrm{Dr}$. P. Reiff for the AE data, Dr. A. Pedersen for GEOS-1 data, and Dr. F. Rich for the S3-3 retarding potential analyzer data. We would also like to thank Dr. M. Kivelson for many helpful comments and Drs. T. Fritz, K. Pfitzer, and W. Olsen for useful discussions. The workshop from which this paper resulted (CDAW 2.1) was supported by ISF and NASA. The analysis of the July 29, 1977 event at Aerospace was funded by the Atmospheric Sciences Section of the National Science Foundation ATI 78-03600. The analysis of the GEOS-1 Ion composition data was supported by the Swiss Nat1onal Science Foundation. 
This Page Intentionally Left Blank 
ABSTRACT.......................................... v

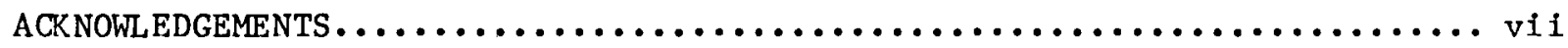

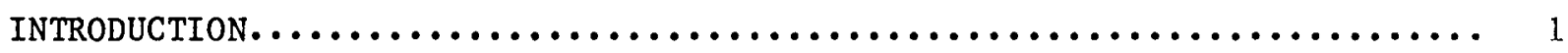

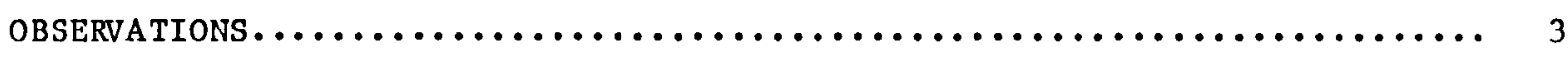

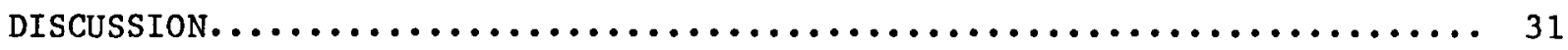

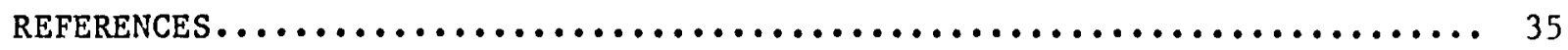


This Page Intentionally Left Blank 
1. Kp and Provisional Dst Indices for July $28-30,1977 \ldots \ldots \ldots \ldots \ldots$

2. Three-Dimensional Mass-Energy Spectra Taken by GEOS-1 in the Magnetosheath on July 29, 1977..................... 5

3(a). Spectra from ATS-6 Plasma Detector Prior to and After the Arrival of Shock at 0027 UT July $29,1977 \ldots \ldots \ldots \ldots \ldots \ldots \ldots \ldots \ldots 7$

3(b). Ion and Electron Spectrograms from July $29,1977 \ldots \ldots \ldots \ldots \ldots \ldots \ldots 8$

4(a). Spectrogram of Particles and Wave Data from the S3-3

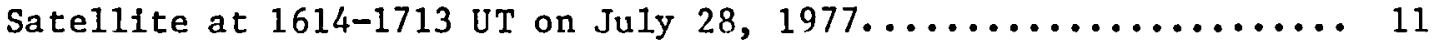

4(b). EXB Plasma Flow Over the Northern Polar Region on July 28,1977 from S3-3 Satellite...................... 12

5. Low Iatitude Edge of Polar Cap as Determined by S3-3 Satellite observations............................. 14

6. Sample Ion Density Profiles from the Ion Retarding Potentlal Analyzer on the s3-3 Satellite................. 17

7. Low Altitude Estimate of the Plasmapause Boundary............ 19

8. GEOS-1 Electron Density Profiles from the Wave Experiment and Integrated Electron Flux Profiles from the Suprathermal E1ectron Detector................................. 22

9(a). Ion Flux Profiles Near Local Evening from GEOS-1............ 23

9(b). Local Evening Ion Density Profiles from the Lockheed

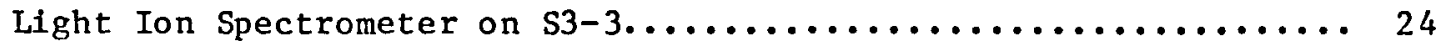

10(a). Example of the $E_{p}>80 \mathrm{keV}$ Precipitation Boundary............ 27

10(b). Equatorward Edge of Precipitating, Energetic $\left(E_{p}>80 \mathrm{keV}\right)$ Ring Current Ions from the Aerospace Proton Tetescope......... 28

11. Inner Edge of the Plasmasheet Electrons at Low Altitude........ 29 
Introduction

July 29, 1977 was chosen by the members of the International iagnetospheric Study (IMS) committee for detalled study for several reasons, the nost important of which were that several substorms occurred on that day and the magnetopause boundary was compressed to altitudes of $\sim 6.6-7.0$ Re after the arrival of an interplanetary shock at 00:27 UT (Knott et al., 1981). Later in the day the interplanetary field turned northward, the magnetosphere quieted and the polar cap "collapsed" to a very small area. Auroral precipitation was observed as high as $\Lambda \sim 85^{\circ}$. So, the day contained very strong activity and very rapid changes of magnetosphere boundaries. These phenonena Indicate that July 29, 1977 was a very unusual day, being both very disturbed and very quiet with a highly compressed and an inflated magnetosphere at different times of the day. The day was also of interest to the scientific community because a very large number of simultaneous ground and satellite measurements were available. The nearly complete in situ coverage provides a unique opportunity to present a detailed picture of a disturbed period. The set of observations can be used to set boundary conditions for and test the many aspects of magnetospheric models.

The purpose of this report is to draw together the information available from the various in situ plasma measurements and to try to put them into a coherent picture of the state of the magnetosphere. To this end the measurements will be used to locate the varlous plasma "boundaries", such as the plasmapause boundary, trapping boundary, inner edge of the plasma sheet and ring current, and the polar cap boundary. These boundaries reflect the dynamics of the magnetospheric processes such as convection and substorms and their motions can be used as diagnostics of the magnetosphere on a large scale. 
Ubservations

The magnetospnere was undisturbed prior to 0000 UT on July 29, 1977 as evidenced by the $\mathrm{kp}$ and provisional Dst shown in Figure 1 . The substorm event was inltiated by a strong shock wave in the solar wind as is evidenced by the positive excursions in Dst and the midlatitude magnetometer stations at about 0028 UT on July 29 (Manka et al., 1981). The resulting solar wind density and velocity increases were sufficient to push the magnetopause past GEOS-1, which was at $\sim 7$ Re near local noon, but not past ATS-6 in the post noon reg10n (ilanka et al., 1981; King et al., 1981; Knott et al., 1981; Wilken et al., 1978; Wilken et al., 1981).

The shock wave was followed by a substorm with a slow (few hours) time scale. The ring current is greatly enhanced as is indicated by Dst minlmizing at $\sim-100 \gamma$ in Figure 1. A second substorm occurred near 0600 UT and a third near $1200 \mathrm{UT}$. The third substorm caused a secondary minimum in Dst during the recovery from the initial substorm (see Fig. 1). From 1500 UT on, the low and midlatitudes of the magnetosphere returned to relatively quiet conditions while the Dst recovery proceeds until about 0200 UT on July 30 . In all, four distinct substorms were seen with maximum field depressions at 0430, 0630, 0900 and 1230 UT (Manka et al., 1981). Each substorm left its own signature in the plasma boundaries.

The evidence for the close approach of the magnetopause is shown in Figure 2 as a sudden appearance of relatively intense $\mathrm{He}^{++}$fluxes at GEOS-1. At this time GEOS-1 was near its apogee on the dayside magnetosphere near 13 IIIT. Figure 2 shows four complete suprathermal (60 eV - $16 \mathrm{keV}$ ) ion spectra for the period when the magnetopause crossed GEOS-1 following the solar wind 


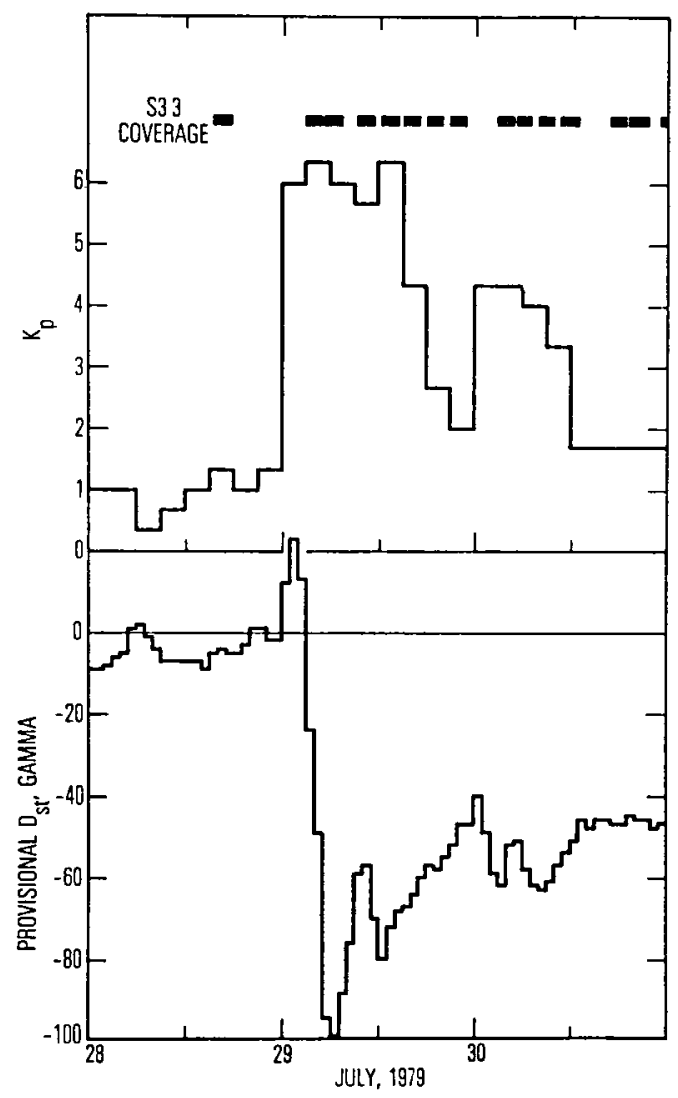

Figure 1. Kp and Provisional Dst Indices for July 28-30, 1977. The periods of s3-3 satellite data are shown as bars across the top of the figure (from Fenne11 et a1., 1979). 


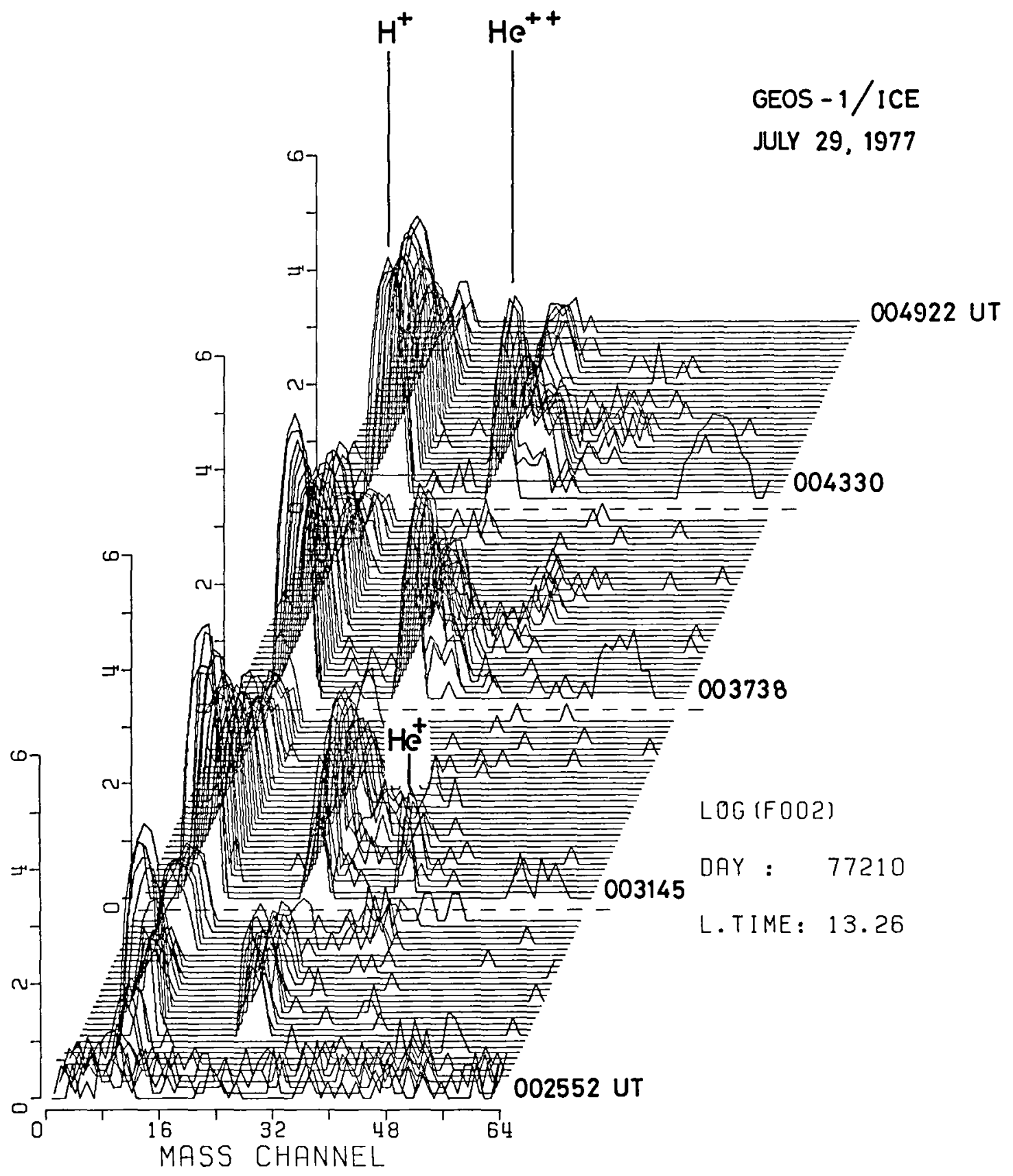

Figure 2. Three-Dimensional Mass-Energy Spectra Taken by GEOS-1 in the Magnetosheath on July 29, 1977 (after Geiss et a 1., 1978). 
shock at $\sim 0027$ UT. The crossing occurred at 0027:55 UT and was preceded by sharp spikes of ion flux at 0026:44 and 0026:56 UT. Analysis of the ion energy spectra indicates that the spikes may represent a flow of particles consistent with a compression associated flow of ions as the magnetopause moves inward (Knote et al., 1981). The GEOS-1 satellite remained in the magnetosheath from at least 0027 UT to 0149 UT when data coverage ended (see Geiss et al., 1978; Wilken et al., 1978). The figure shows the high :1/Q component of the solar wind which extends dragonally away from the ${ }^{4} \mathrm{He}^{+2}$ peak toward higher mass and energy. The detailed analysis of the data, described by Geiss et al. (1978), showed the existence of ${ }^{3} \mathrm{He}^{2+}, 0^{+6}$, sillcon group ions and some iron group lons. These ions are all solar wind ions, not ionospheric. A weak flux of $\mathrm{He}^{+}$is present from 0032-0033 UT with a few hundred $\mathrm{eV}$ energy. At $0136 \mathrm{UT}$ a simflar observation is made of $\mathrm{O}^{+}$(Knott et al., 1981). Thus there is a suggestion of magnetospheric plasma with different ion makeup and origins from that of the solar wind.

Careful examination of the ATS- 6 plasma data shows that the magnetopause did not penetrate inside its orbit, $1 . e .$, magnetosheath plasma was not encountered (ref. Figure 3b). ATS -6 is in the post noon sector at this time near $15 \mathrm{LT}$ and $3^{\circ}$ above the geomagnetic equator. Enhanced low energy fluxes of both ions and electrons appeared at 0027 UT (ref. Fig. 3). However, Wilken et al. (1978) noted that the $>25 \mathrm{keV}$ protons showed an enhanced and continued presence consistent with an adiabatic increase of the particles possibly resulting from a field compression caused by the shock, but that ATS- 6 remained in the magnetosphere. Thus, it is most likely that the enhanced low energy fluxes represent a boundary layer encounter.

Later in the day near 0320-0340 UT ( 1800 LT) ATS-6 is passing from the plasmasphere to the plasma sheet. The crossing is not smooth but accompanied 


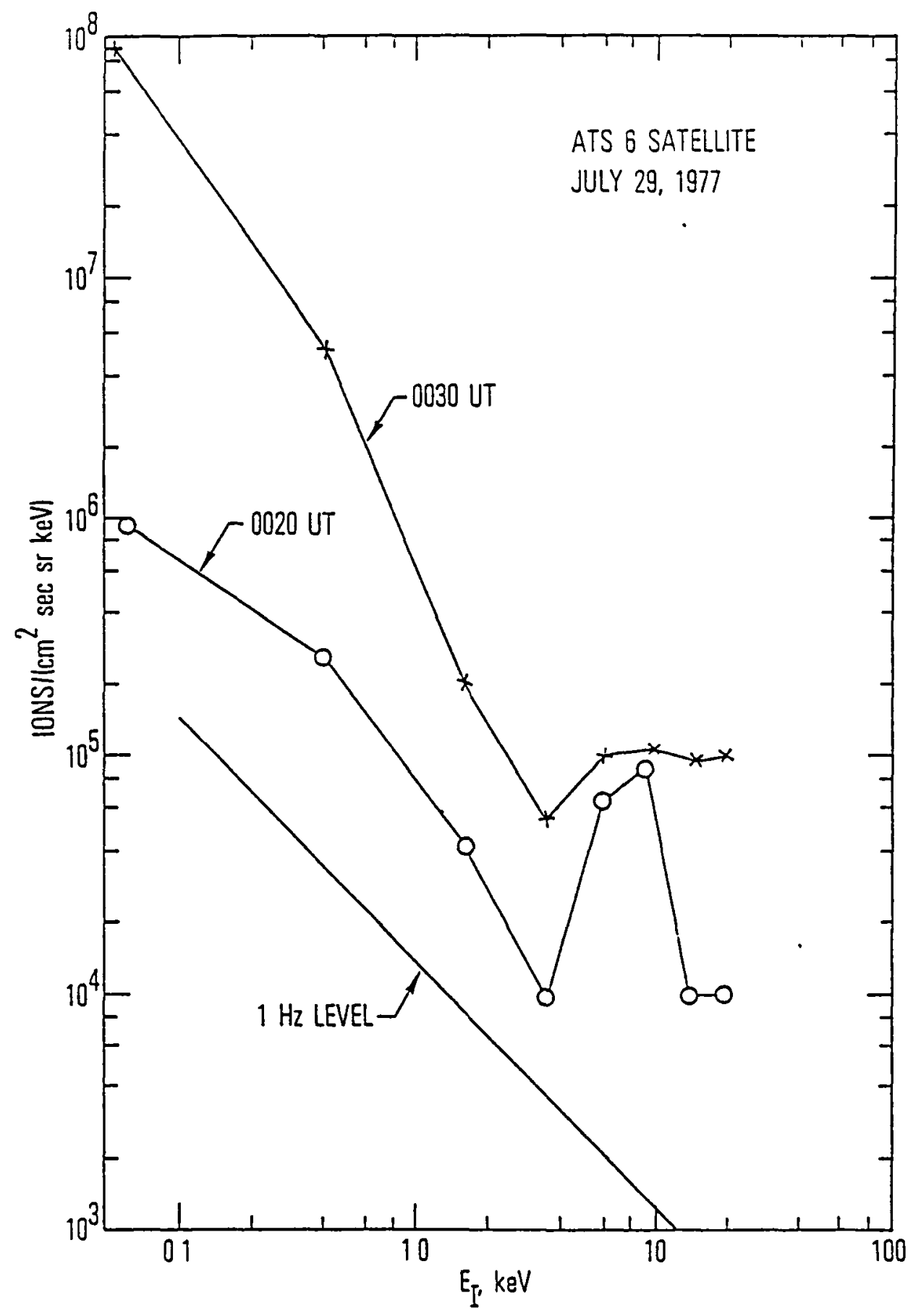

Figure 3(a). Spectra from ATS-6 Plasma Detector Prior to and After the Arrival of Shock at 0027 UT July 29, 1977. Instrument field of view is oriented to look north of the orbital plane at $\sim 75^{\circ}$. 


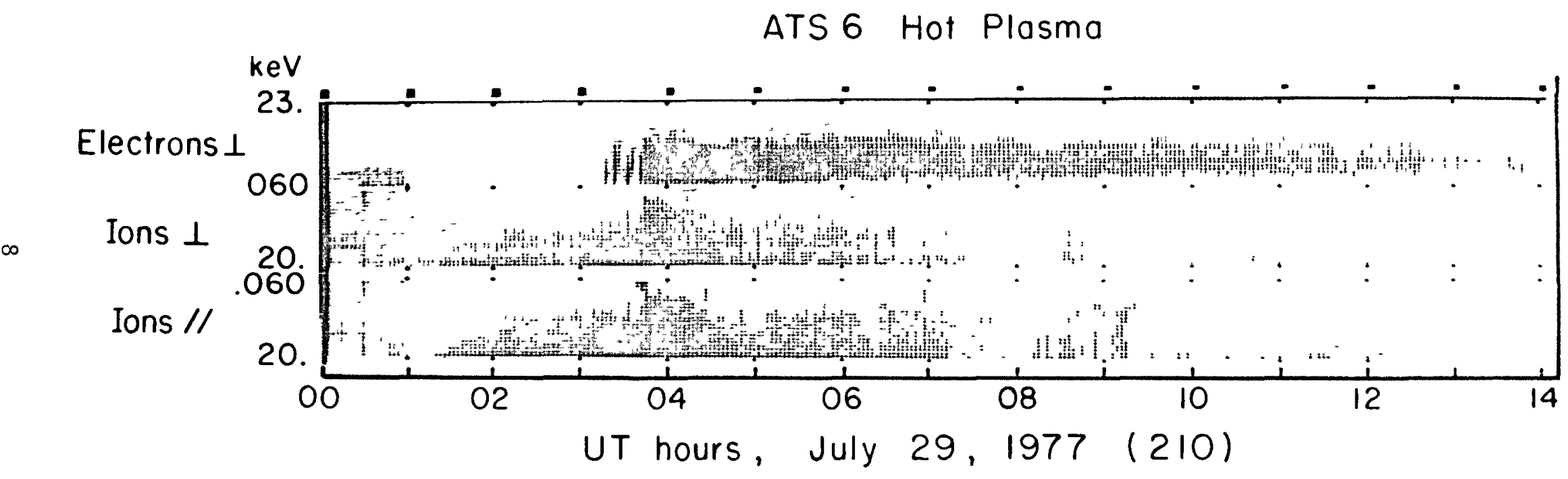

Figure 3(b). Ion and Electron Spectrograms from July 29, 1977. The ATS-6 sate11ite is near $1500 \mathrm{LT}$ at $0030 \mathrm{UT}$. The particle intensity is proportional to the darkness of the spectrogram. Upper electron and ion spectrograms are from detectors pointing approximately perpendicular to the magnetic field. The lower ion spectrogram is from a detector pointing nearly parallel to the field. 
by auliple electron increases as shown in Figure $3 b$. The satellite is near the longltude of the College Alaska magnetometer which shows a small negative Fluctuation at this time (see Manka et al., 1981). Enhanced $60 \mathrm{eV}$ ion fluxes (ref. Fig. 3b) are observed in the nominally parallel detector but not in the perpendicular detector. This is an Indication of field aligned streaming of ionospheric ions at the plasma sheet boundary.

The other major features seen in the ATS- 6 plasma data are the decrease increase of electrons and ion fluxes near 0800-0900 and 1130-1200 UT (see Figure 3b) in association with large magnetıc bays at College (Manka et al., 1981). In fact the flux decreases precede the substom onset and the flux recovery occurs at the onset. The effect is greatest on the more energetic plasma ions $\left(E_{I} \sim 5-20 \mathrm{keV}\right)$. The ion decrease is dispersive, $i . e .$, occurs first at the highest energies, whereas the ion recovery shows no dispersion. The final ion fluxes are not significantly higher than the initial fluxes. There are ion flux Increases at $<400 \mathrm{eV}$ after the recovery, which way be Indlcative of field aligned fluxes assoclated with the substom (Fennell et al., 1981; Kaye et al., 1981).

One of the magnetospheric boundaries which is of great interest is the polar cap boundary. This boundary defines the region of "open" field lines and is used as a reference in some substorm models. There are several techniques for defining this boundary, such as changes in the angular distribution of solar particles (Vampola, 1971; McDiarmid et al., 1972) and features in the solar flare protons at high latitudes (Evans and Stone, 1969; Fennel1, 1973). The low latitude limlt of the "polar rain" fluxes, which are the tail lobe fluxes and which can show a cutoff just above the auroral fluxes (Winningham and Heikkila, 1974; Meng and Kroehl, 1977; Mizera and Fennell, 1978), have also been used to define the polar cap. The reversal of the plasma 
convection from sunwasd to antisunward Torbert et al. (1981), and poleward termination of the low-energy ion and auroral electron precipitation, as a definition of the poleward extent of the auroral oval which bounds the polar cap (Meng, 1979), are other features used to estimate the polar cap boundary. These determsnations are easiest to make from low altitude polar orbiting sateliftes such as the $\$ 3-3$. The reader should refer to the referenced papers for a detailed description of the techniques involved. In this study we have used only the last three since the other measurements were not available.

Figure 4 shows a spectrogram (Mizera and Fennel1, 1977; Fennell et al., 1979) of the low altitude S3-3 auroral electrons and low energy ion precipitation for July 28, 1977 near 1700 UT. The poleward termination of the auroral electrons and lons is very obvious at $\sim 61270 \mathrm{sec}$ UT and $\Lambda \sim 74.2^{\circ}$ on the evening side. On the morning side the soft electron fluxes at 1 keV show a sharp drop near $59440 \mathrm{sec}$ at $\Lambda \sim 72.5^{\circ}$ with only "polar rain" observed at higher latitudes. Similar data were available from the Lockheed particle experinent on S3-3 (Sharp et al., 1979) and were used as an independent determination of the boundary.

The correspunding plasma flow data is shown in Figure $4 b$. This figure shows one example of the plasma flow in the northern hemisphere on 28 July 1977. The flow vectors were deduced from the measured electric field in the spin plane of the satellite which is maintalned close to the orbital plane (for details see Nozer et al., 1979; Mozer and Torbert, 1980). Hence, these flow vectors consticute only the flow component normal to the satellite trajectory, which runs from near 0340 to about 1800 MLI past the night side of the pole. The flow vectors are perpendicular to the trajectory except for a slignt rotation which arises from the projection of the electric field to a 


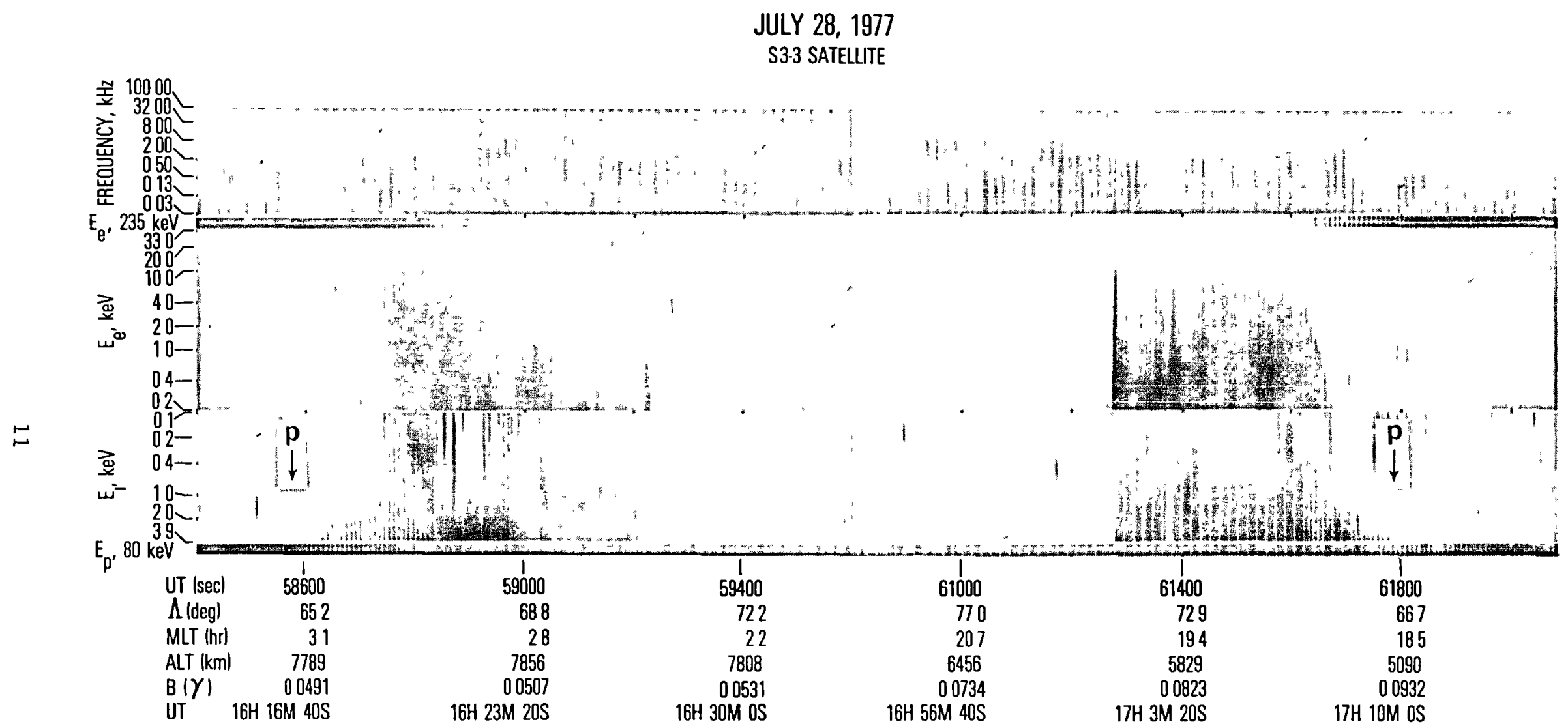

Figure 4(a). Spectrogram of Particles and Wave Data from the S3-3 Satellite at 1614-1713 UT on Ju1y 28, 1977. PP indicates position of plasmapause based on inner edge of plasma sheet ions in the keV energy range. 


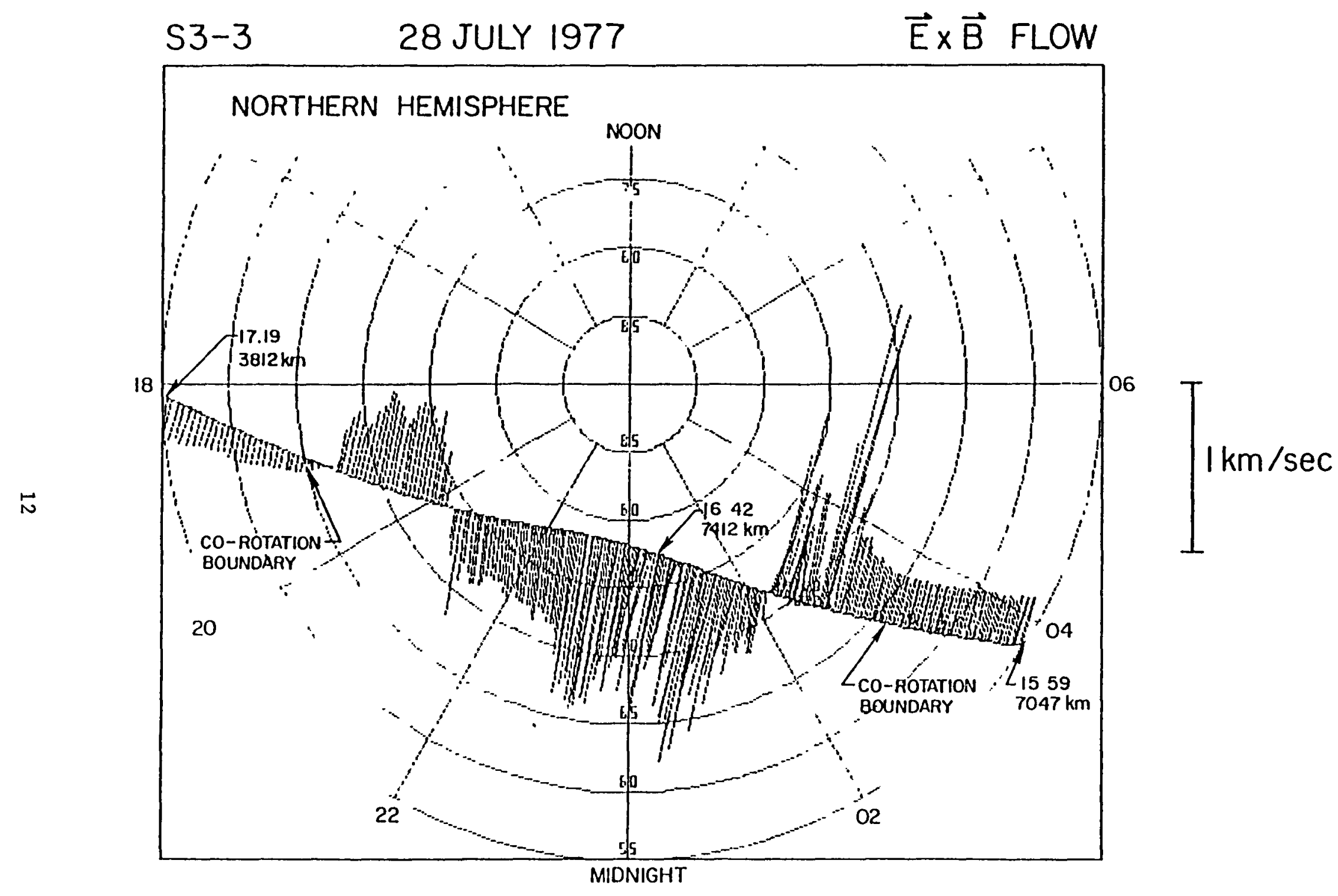

Figure 4(b). EXB Plasma Flow Over the Northern Polar Region on July 28, 1977, from s3-3 Satellite. See text for details. 
fixed altitude by equipotentral mapping. The flows change from sunward to antisunward at $\Lambda \sim 74^{\circ}$ on the evenzng side and $\Lambda \sim 72^{\circ}$ on the worning side. (ref. Torbert et al., 1981 for description of polar cap boundary determanations). These are in good agreement with the particle boundaries deduced above.

The electron, ion and electric field data from the $\$ 3-3$ experiments were used to determine the polar cap boundaries as described. The results are shown in Figure 5. The electric field data was available on only about $50 \%$ of the auroral traversals. The Aerospace points correspond to the best estimate using both electron and ion data. The Lockheed points correspond to electron boundaries only.

The high latitude magnetosphere remains disturbed during the 1500-2400 UT recovery period. This disturbed condition is reflected in the data as intense auroral-1ike precipitations observed at high latitudes. The retreat of the active regions to high latitudes late in the day is evidenced in the particle precipitation by the extremely high latitude reached by the polar cap boundary. Especially note that the solid and open points near 1900 and 2200 UT on July 29 indicate that the S3-3 satelite did not attain latitudes high enough to penetrate Into the polar cap (see also Figure 2 of Fennell et al., 1979). The polar cap boundary then recovered to $\Lambda \sim 73-74^{\circ}$ by 0400 UT on July 30 . Thus, during the storm recovery period, the polar cap boundary moved up above $\Lambda=85^{\circ}$, which is very high indeed. A separate paper in this series presents all the evidence pertaining to this event (Zanettl et al., 1981).

Based on the particle data one could argue that the satellite may have entered the polar cap for a few minutes near 1910 UT and $\Lambda \approx 77^{\circ}-78^{\circ}$ as shown by the dawn side data point (Ref. Zanetti et al., 1981 and Fig. 2 of Fennell et al., 1979). Simlarly, the electric field data shows multiple reversals 


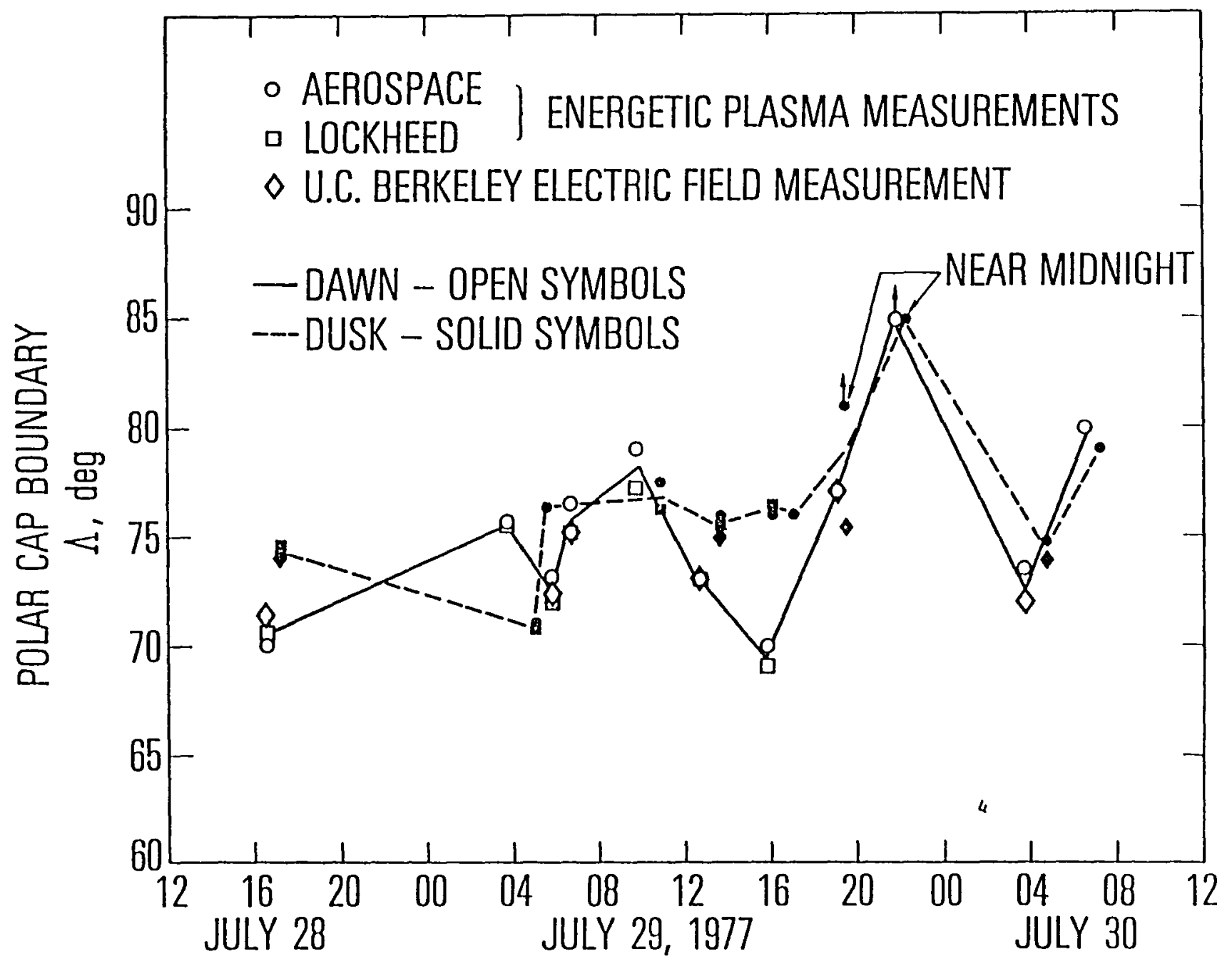

Figure 5. Low Latitude Edge of Polar Cap as Determined by S3-3 Satellite Observations. The circles are estimates of the polar cap boundary from the Aerospace plasma experiment. The diamonds are the electric field reversals from the U.C. Berkeley electric field experiment. The squares are the estimates of the boundary from the Lockheed particle data. 
toward higher latitudes where the particle precipitation is observed. Near 2200 UT there is no indication in the particles of an entry into the polar cap. In fact, precıpitatıng $>1 \mathrm{keV}$ ions are seen up to $\Lambda \sim 85.7^{\circ}$. Unfortunately there are no electric field measurements for this tume. There is other evidence, primarily from ground based data, that shows the strong auroral activity had moved to high latitudes (Zanetti et al., 1981).

As can be seen, during the disturbed times the polar cap boundary moved in response to the magnetic activity. The details of the motion are not resolvable in the low altitude satellite data although the general trends are evident. The highest latitudinal excursions occurred durfing the recovery perıod, after 1800 UT on July 29, following the substorms earlier in the day. The boundary then moved back to low latitudes in response to the substorm starting near 0200 UT on July 30 and again moved poleward during the later recovery. The substorms early in the day came too close together, compared to the satellite orbital periods, to get a complete plcture of the polar cap response.

There are several other plasma boundaries which are inportant in terms of electric and magnetic field models of the magnetosphere. The plasmasphere boundary is controlled by the convection electric fleld and its temporal variation is an important measure of the variation in the magnetospheric convection field and the plasma response to the variations. The plasmasphere boundary is usually determined by measuring the plasma density to find the $L$ shell and/or altitude at which the density falls dramatically from $100-$ $1000 \mathrm{~cm}^{-3}$ to the "trough" values of less than one to a few tens of ions $\mathrm{cm}^{-3}$. This is the principal definition of the plasmasphere boundary used in this study. 
The measurements available on July 29 are of several different kinds at low altutude. First there is the electrıc field measurement which distinguishes the corotation region from the non-corotating region, then there is the measurement of an enhanced flux of $90-4000 \mathrm{eV} / \mathrm{q}$ 1ons ( 1 to 2 orders of magnitude flux increase above normal levels) at small $\mathrm{L}$ shells and finally there is a measurement of ion density from a retarding potential analyzer. Examples of some of these data and the estimated plasmapause boundary are shown in Figures 4 and 6 .

Figure $4 a$ shows the particle data for a dawn-dusk traversal from low latitude across the polar cap and back towards the equator. The termination of the enhanced low energy ion fluxes (bottom spectrogram panel), indicative of exit from the plasma sheet into the plasmasphere, occurs just below $\Lambda=65^{\circ}$ near $3.1 \mathrm{MLT}$ and about $\Lambda=67^{\circ}$ at $18.5 \mathrm{MLT}$ (see arrows). Since this is a relatively quiet period $(\mathrm{Kp}=1+$ to $2-$; Dst $=-4$ to -5 ) the inner edge of the plasma sheet 1ons is not as obvious as in the disturbed data because of the lower ion flux levels (for other examples see Fennell et al., 1979). This spectrogram is derived from the Aerospace particle data. The equatorward edge of the enhanced plasma sheet zons is also seen in the Lockheed ion data as shown in Figure $9 \mathrm{~h}$.

The electric field experiment on the $53-3$ satellite was used to obtaln the EXB flow at low latitudes too. In the plasmasphere the flow is normally consistent with that expected from the corotation, with the earth's field, of the cold plasma past the satellite. As the satellite proceeds poleward through the plasmapause the flow changes consistent with the fact that the plasma sheet plasma is not corotating. This change is used to define the corotation boundary (see Mozer and Torbert, 1980). In Figure 4b the corotation boundaries determined in this manner are consistent with plasma corotation below $\Lambda \sim 65^{\circ}$ in the dusk and $\Lambda \sim 64^{\circ}$ in the morning sectors. 


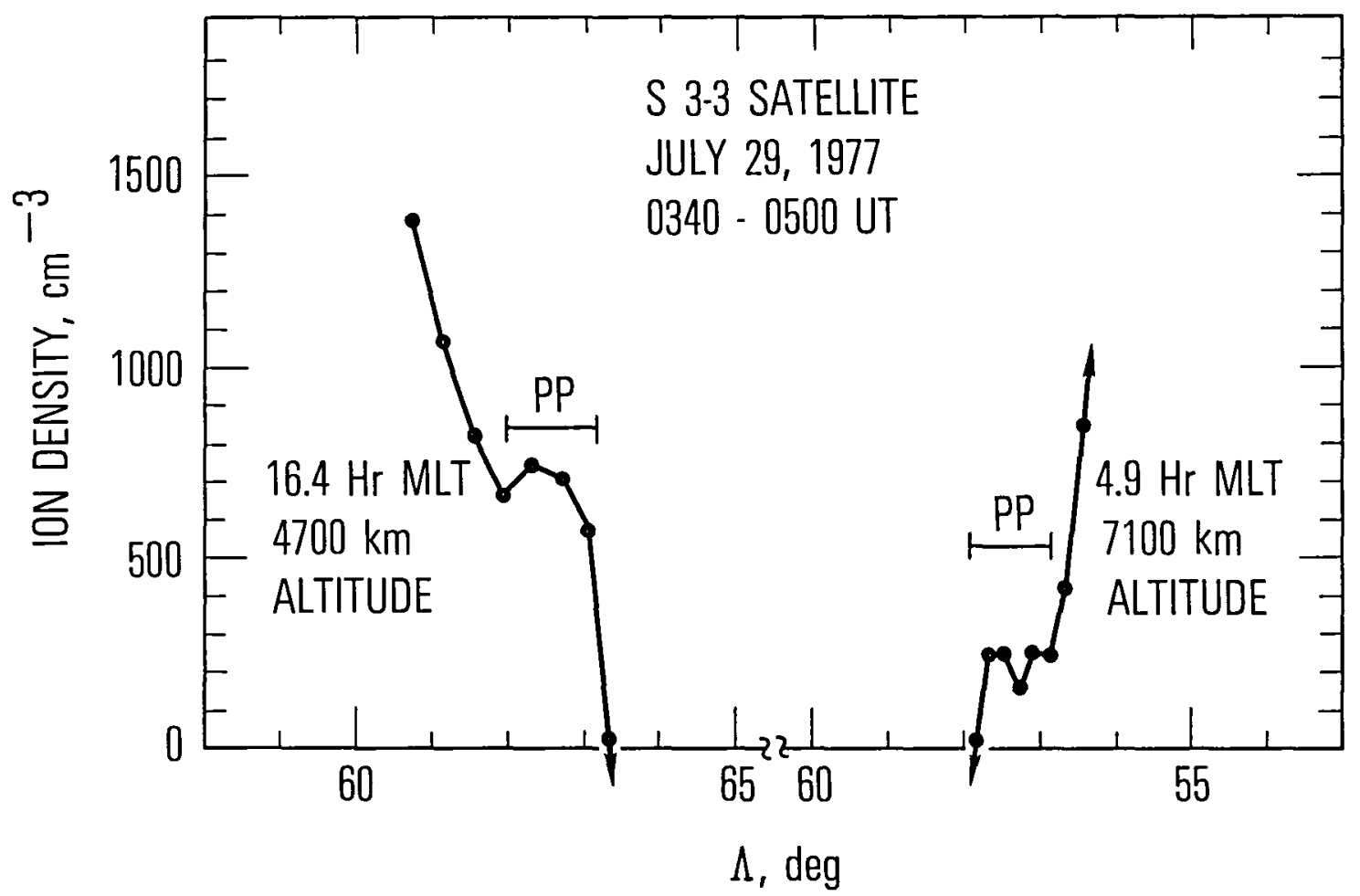

Figure 6. Sample Ion Density Profiles from the Ion Retarding Potential Analyzer on the S3-3 Satellite (Burke et a1., 1980). 
Figure 6 shows a plot of $10 n$ densities from the s3-3 retarding potential Ion analyzer on July 29, 1977 (for a description of this Instrument ref. Burke et al., 1980; Wildman, 1977). The local morning and evening plasmapause crossings are indicated. Although the density gradients of the plasmaspnere boundary are relatively steep during this time there is already an intermediate density "shelf" formed near $700 \mathrm{~cm}^{-3}$ and $250 \mathrm{~cm}^{-3}$ on both the local evening and morning sides respectively. Note that the ion density is available only every $\sim 20 \mathrm{sec}$ (once every satellite rotation).

The plasmapause boundary during this disturbed period is often not well defined even in the ion density data. The density data often show a very slow variation with invariant latitude and have regions of elevated $(\gtrsim 100$ ions $\mathrm{cm}^{-3}$ ) density extending over $3-6$ degrees. Such times are indicated by the length of the bars in Figure 7 for the plasmapause boundary. There are also obvious differences between these positions on the morning and evening side of the magnetosphere. The ion retarding potential analyzer also shows that a hot enhanced plasma is present outside of and overlapping the plasmasphere boundary. This is evidenced by a peak in the measured ion current not only in the ram drection but also in the wake when the instrument field of view is perpendicular to $\underline{B}$. This is assumed to be an enhanced plasma sheet plasma which is discussed below.

The resulting estimates of the low altitude plasmapause boundary using the different techniques are shown in Figure 7. Generally, the particle and electric field estimates are in good agreement (within $\sim 2^{\circ}$ ) except near 1330 UT and 1800-2000 UT. The electric field estrate near 1830 is an upper limlt. The point at 1330 UT would seem to indlcate that the plasma inside the boundary of the high density region (based on ion density) is not corotating over a farly large radial distance. At this same time the plasma density 


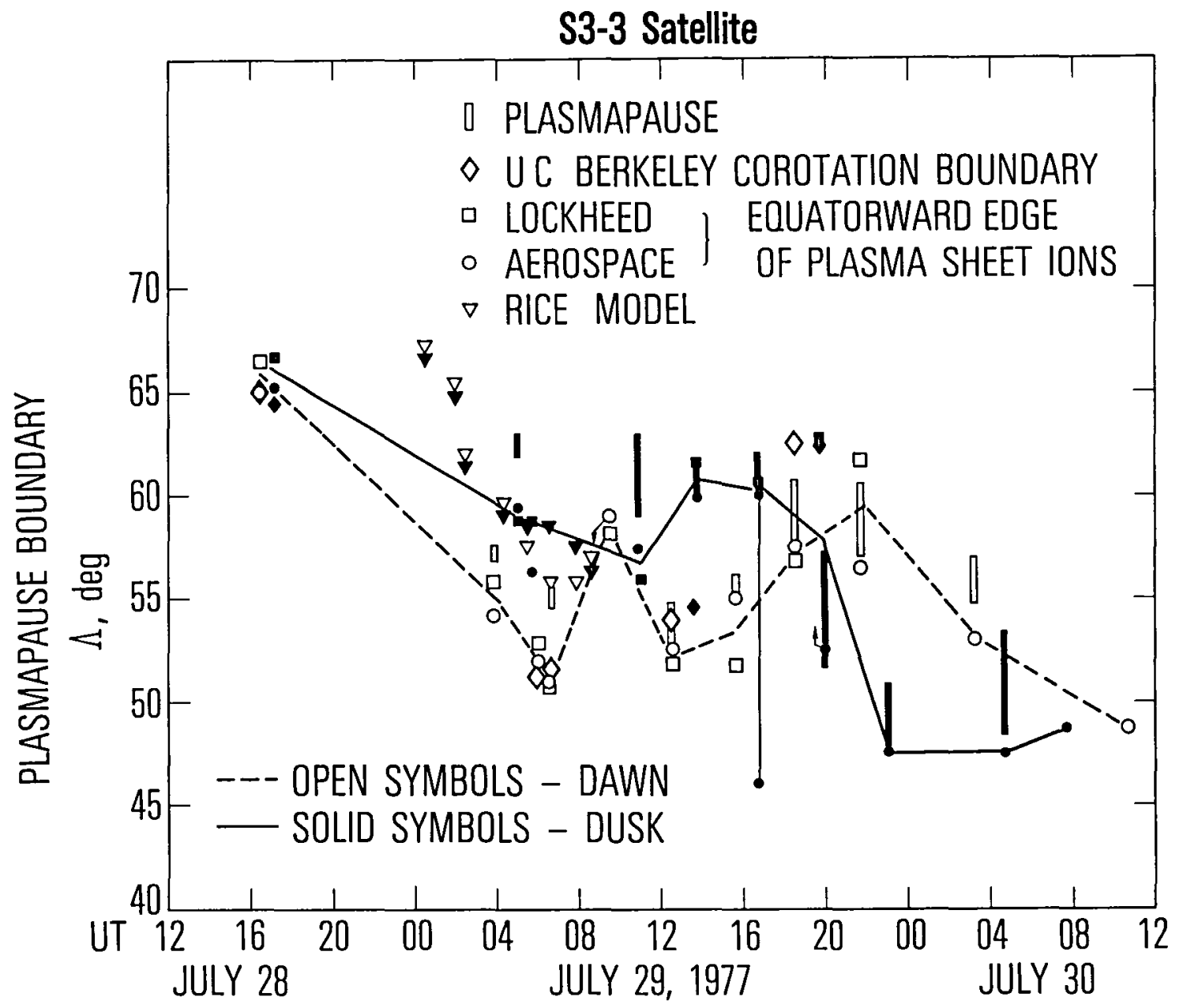

Figure 7. Low Altitude Estimate of the Plasmapause Boundary. The circles and squares correspond to the inner edge of the plasmasheet ions as determined by the Aerospace and Lockheed ion measurements. The diamonds are the corotation boundary points from the U.C. Berkeley electric field experiment. The vertical bars are the boundary points estimated from the ion density data (data provided by $F$. Rich of Alr Force Geophysics Laboratory). 
data show that an intense low energy ion flux is observed, when the instrument view is perpendicular to $\underline{B}$ in. the satellite wake, while crossing the plasmapause and at hizher latıtudes. At the same place, the energetic plasina analyzer shows a response to heavy ions $\left(\mathrm{He}^{+}, \mathrm{O}^{+}\right.$) as described in Fennell et al. (1979) (see also the discussion of Figure 9b below).

The plasma sheet ion boundaries from the Aerospace and Lockheed instruments are in relatively good agreement. The differences that exist may be related to the different energy bounds on the two instruments $(0.09-4.0$ $\mathrm{keV} / \mathrm{q}$ for the Aerospace and $0.5-16 \mathrm{keV}$ for the Lockheed measurements). It is apparent from Figure 7 that the plasma sheet ion boundary is generally on the low latitude side of the plasmapause boundary, as estimated from the Ion density data. The agreement between the plasmapause boundary derived from the density measurements and that derived from the energetic ion measurements is quite good after 1200 UT on July 29, 1977. Prior to that tine the plasmasphere would seem to have an intense $90 \mathrm{eV}$ to $16 \mathrm{keV}$ 1on component present in its outer regions.

What is clear from Figure 7 , regardless of which boundary estimate is used, is that the low altitude plasmasphere boundary moved from its normal position, near $\Lambda \sim 63^{\circ}-66^{\circ}$ ( $\mathrm{L} \sim 5$ to $6 \mathrm{Re}$ ), towards the earth to as low as $\Lambda \sim 45^{\circ}-55^{\circ}$ (2 to $3 \mathrm{Re}$ ) in response to the substorms.

The large separation between the two solid circle points near 17 UT on July 29 (Figure 7) represents the high latitude edge of the continuous enhanced plasma region and the low latitude edge of a "detached" enhanced plasma region. The "detached" plasma consists of ions with energies below 2-4 keV. The plasta instruments' response indicates there is a dominance of heavy ions in the 'detached' fluxes (Fennell et al., 1979). Careful examination of 
the Ion density data shows that there is an intense flux of low energy $(<100$ ev) Ions seen perpendicular to $\underline{B}$ in the satellite wake, at least down to $\Lambda \sim 55^{\circ}$. At $\Lambda \sim 55^{\circ}$ the lons measured by the low-energy plasma experiment Increase in energy from a maximum of $\sim 1 \mathrm{keV}$ to $2-3 \mathrm{keV}$. Thus, they may not be observable by the ion density measurement. Also, at this point the density is increasing from several hundred to over $10^{3} \mathrm{~cm}^{-3}$ so that the wake peak is no longer resolvable, since the instrument had automatically switched to a less sensitive scale.

At the equator the GEOS-1 satellite data covered the $I$ range $\sim 5.0-7.75$ Re. No plasmapause crossing was observed on the dayside but one was observed near 1700-1800 LT. These data are shown in Figure 8, which shows the electron density from the GEOS-1 wave experiment (Etcheto and Bloch, 1978) and the low energy electron data from the suprathermal plasma analyzers (Johnson et al., 1978).

As is seen in Figure 8, the electron density remained high as GEOS-1 traversed the dayside magnetosphere (0930-1300 UT). This elevated density has been interpreted by Etcheto and Bloch (1978) as a remnant of the plasma from past quiet magnetic conditions which is drufting from the dawn side to the post noon side of the magnetosphere in the post SSC enhanced electric field. On July 29 the electron density data shows that the dusk plasmapause occurs near 1846 UT or $L \sim 3.4\left(\Lambda=57.3^{\circ}\right)$. This is shown in Figure $9 a$ as $\mathrm{n}_{e}=100$ $\mathrm{Cm}^{-3}$ (based on electric double probe data, (Pedersen et al., 1973; Decreau et al., 1978). This is in good agreement with the low altitude plasmapause position taken near 1930 UT. Similarly at 1600-1800 UT on July 28 GEOS-1 crossed the dusk plasmapause near or below $L \sim 7\left(\Lambda \sim 68^{\circ}\right)$. Again in good agreement with the upper limlt of the low altitude boundary (Ref. Fig. 7). 


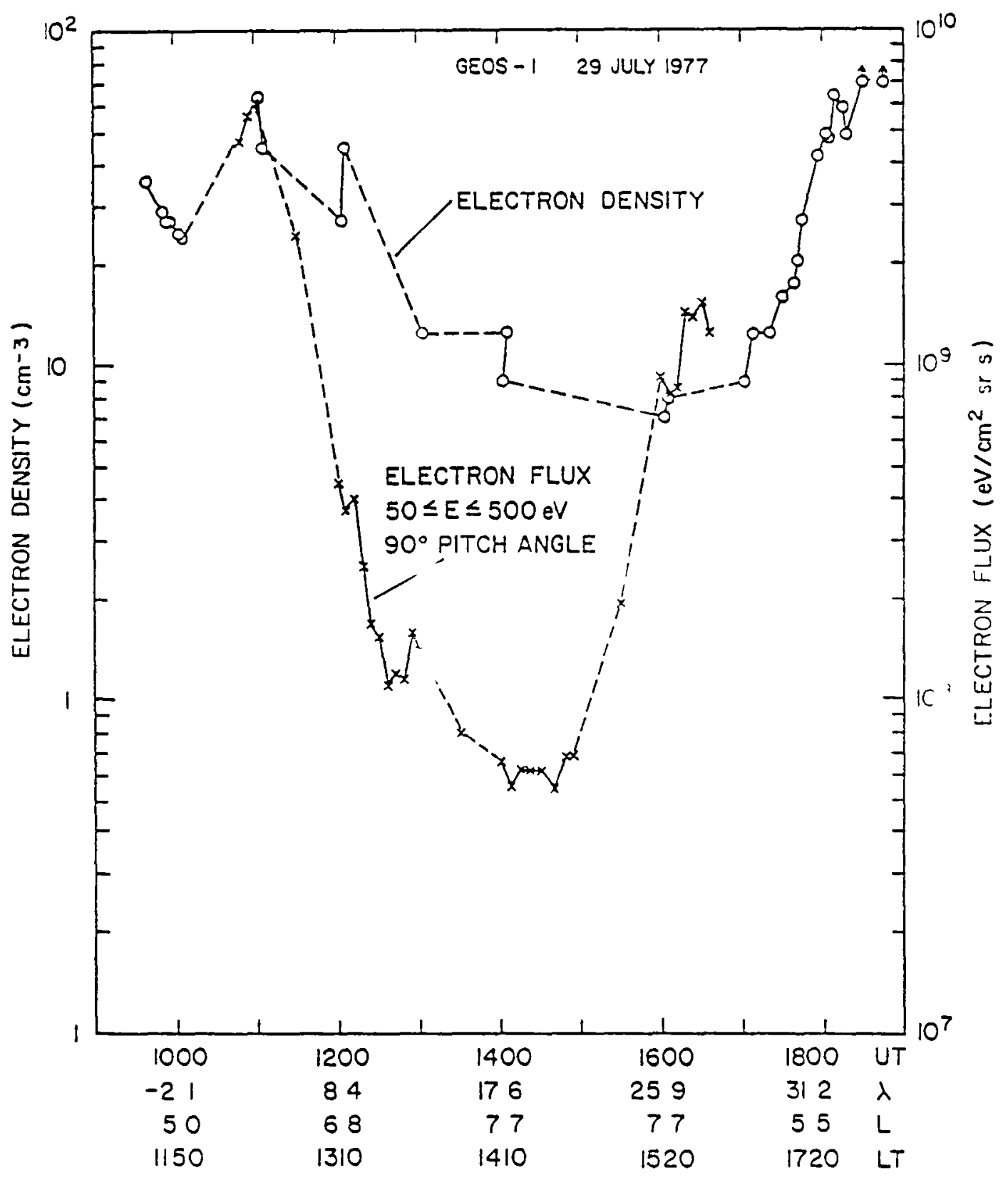

Figure 8. GEOS-1 Electron Density Profiles from the Wave Experiment and Integrated Electron Flux Profiles from the Suprathermal Electron Detector (after Etcheto and Bloch, 1978 and J. F. E. Johnson et a 1., 1978). 


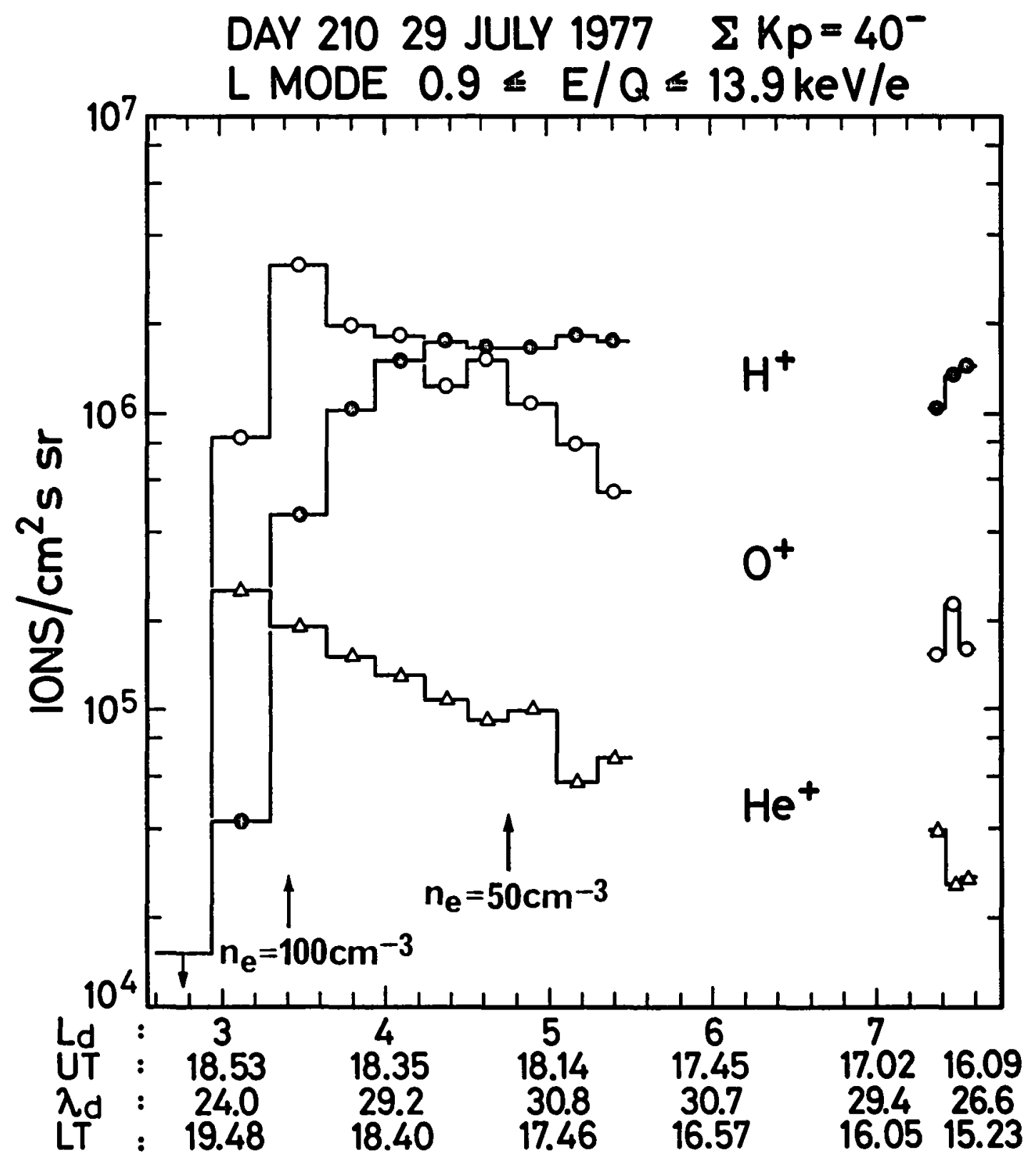

Figure 9(a). Ion Flux Profiles Near Local Evening from GEOS-1 (after Giess et a 1., 1978). Electron densities $n_{e}$ were supplied by the electric field double probe experiment on GEOS-1 (after Pedersen et al., 1978). 


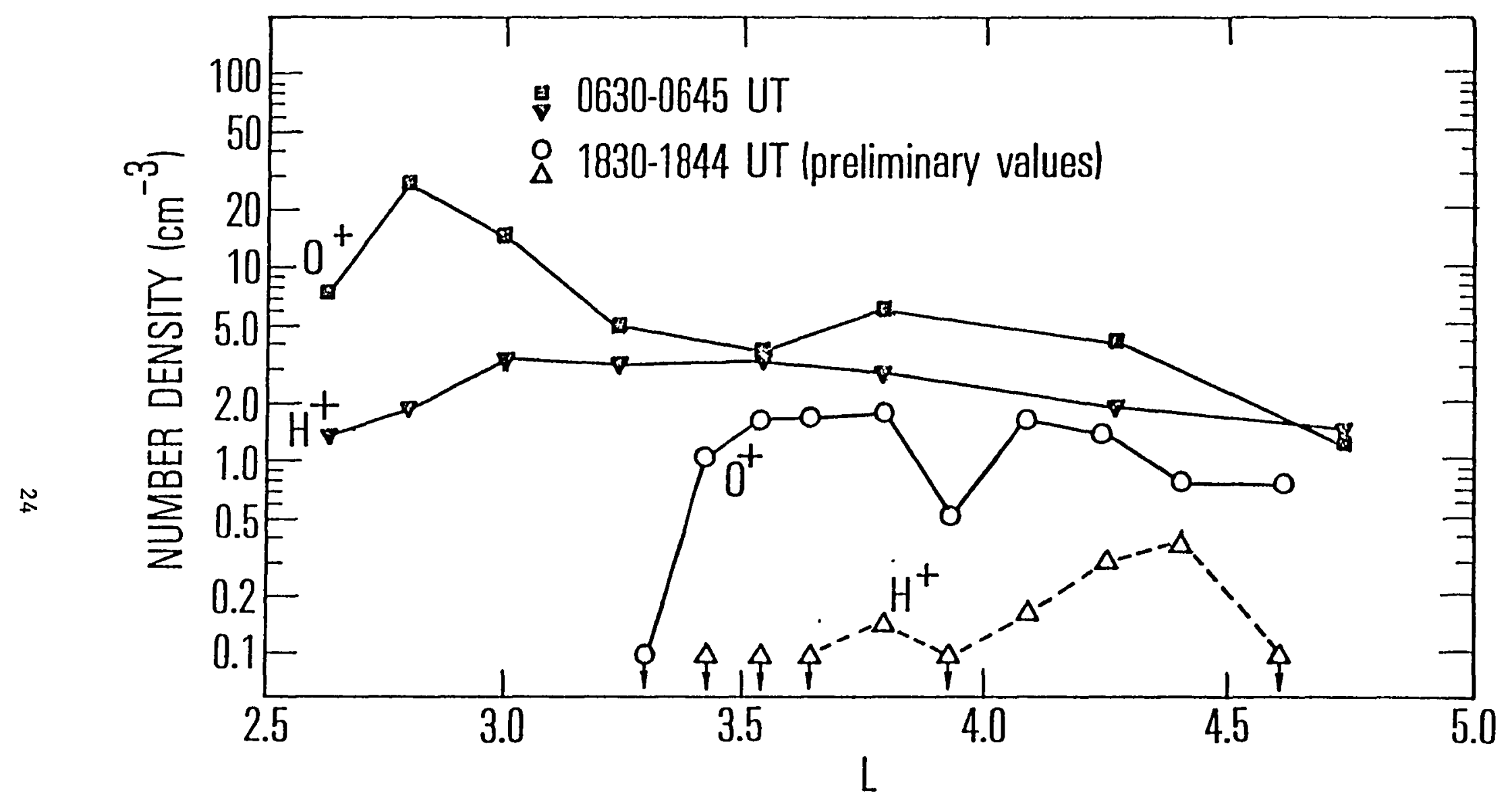

Figure 9(b). Local Evening Ion Density Profiles from the Lockheed Light Ion Spectrometer on S3-3. 
The low altrtude data at $\sim 1700 \mathrm{UT}$, as discussed above, showed that the energetic ion component had penetrated inside the plasmapause as defined by the ion density. At $\sim 1930$ UT the enhanced plasma is seen at the lower edge of the estimated plasmapause boundary (Ref. Fig. 7). In Figure 9a we see that the energetic $\mathrm{H}^{+}$, $\mathrm{He}^{+}$and $\mathrm{O}^{+}$ions exist below the $\mathrm{n}=100 \mathrm{~cm}^{-3}$ boundary down to $I \sim 2.9$. This is analogous to the deep penetration of the low altitude enhanced plasma near 1700 UT (see also Fig. 2 of Fennell et al., 1979).

As mentioned above, the energetic plasma analyzer on $53-3$ responded to an enhanced plasma composed of predominantly heavy lons in the subauroral regions (Fennell et al., 1979). The existence of the heavy lons is demonstrated in Figure 9 which shows data taken by GEOS-1 (Fig. 9a) late on July 29 and the S3-3 Ion composition experıment (Fig. 9b) near the same time and earlier in the day. All three data sets show that oxygen is the dominant ion during the storm and post stom perıod. Moreover, Figure $9 b$ illustrates the recovery phase enrichment of $\mathrm{O}^{+}$relative to $\mathrm{H}^{+}$at $\mathrm{L} \leq 4$ that may be expected on the basıs of charge exchange lifetimes (Lyons and Evans, 1976; Lundin et al., 1980). These data show the energetic $0^{+}$flux and density drop off between $\Lambda \sim 52^{\circ}-53^{\circ}$ near 0600 UT which is in good agreement with the plasmapause boundary determinations in Figure 7. Data from the retarding potential ion analyzers on $53-3$ are consistent with $\mathrm{O}^{+}$being the dominant ion outside the plasmapause in the thermal and suprathermal plasma. These same data show that, at other times inside the plasmasphere, $\mathrm{H}^{+}{ }^{*}$ is usually dominant.

If one assumes similar pitch angle and energy distributions for $\mathrm{H}^{+}$, $\mathrm{He}^{+}$, and $\mathrm{O}^{+}$, then $\mathrm{O}^{+}$is the dominant ion below $\mathrm{L}=5$. The existence of $\mathrm{O}^{+}$as a prime constituent in the magnetosphere just outside the plasmasphere indicates an ionospheric source. This in turn means the lonospherlc lons are accelerated to relatively high energles (few $\mathrm{keV}$ ) during substorms. As a result the inner 
plasma sheet is composed predominantly of lonospheric ions at the lower energies (< $10 \mathrm{keV}$ see Fennell et al., 1981; Kaye et al., 1980; Kaye et al., 1981; and review by R. G. Johnson, 1979 and references there1n).

There are two other plasma boundaries which tend to move in unison under the control of the variable convection field. These are the inner edge of the energetic ring current ion precipitation and the inner edge of the energetic plasma sheet electrons. The inner edge of the ring current ion precipitation was obtained by examining the energetic proton angular distributions to determine the point at which the protons change from showing the effects of strong pitch angle scattering to a trapped distribution (see Figure 10a). The invariant latitude (or L value) at which this occurs was taken as the position of the inner edge. On S3-3 this was determined using $>80 \mathrm{keV}$ proton measurements as shown in Figure 10a. The resultant boundary deterninations are shown in Figure 10b. It has previously been shown that this boundary follows the position of the plasmapause but at about one unit in $L\left[\Lambda=\cos ^{-1}(1 / \sqrt{\mathrm{L}})\right]$ hıgher (izera, 1974). Examination of Figures 7 and 10b show that the upper limit of the plasmapause boundary is $\sim 1.7 \pm 1.1$ Re from the inner edge of the precipitating ring current if we throw out the points near 2140-2300 UT. Prior to 1600 UT the least separation is $\sim 1.2 \pm 0.82$ Re. These are in relatively good agreement with 还zera (1974).

The inner edge of the plasma sheet electrons was observed by both S3-3 (ref. Figure 4a) and $A E-C$. This boundary, as determined using three different sensors, is plotted in Figure 11. To obtain this plot we took the point at which the plasma sheet electron fluxes dropped off as the satelites passed from high to low Latıtudes (Ref. Figure 4 and Fennell et al., 1979). This was done independently for the data from S3-3 and $A E-C$ for each instrument. The most obvious feature is the strong unfform dawn-dusk asymmetry in this boun- 
JULY 29, 1977

S3-3 SATELLITE

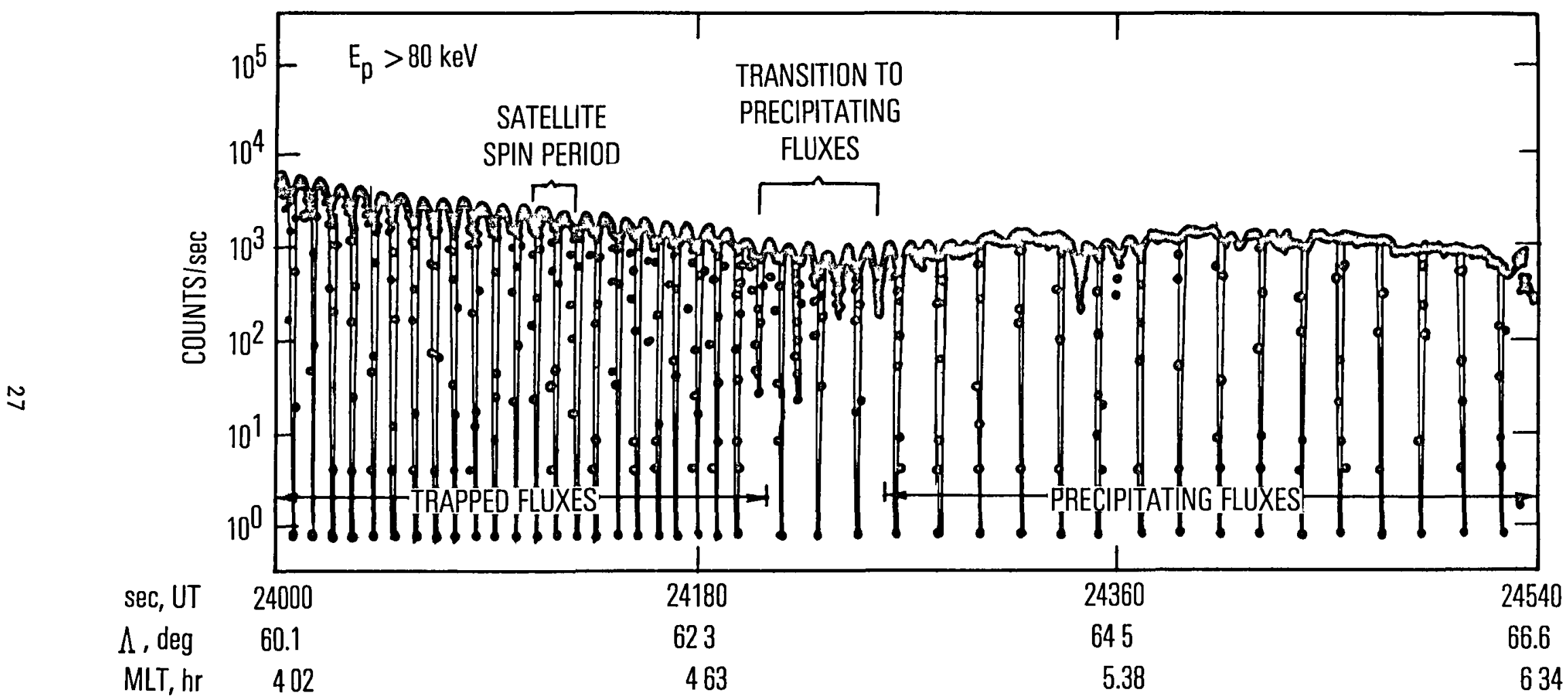

Figure $10(a)$. Example of the $E_{p}>80 \mathrm{keV}$ Precipitation Boundary 


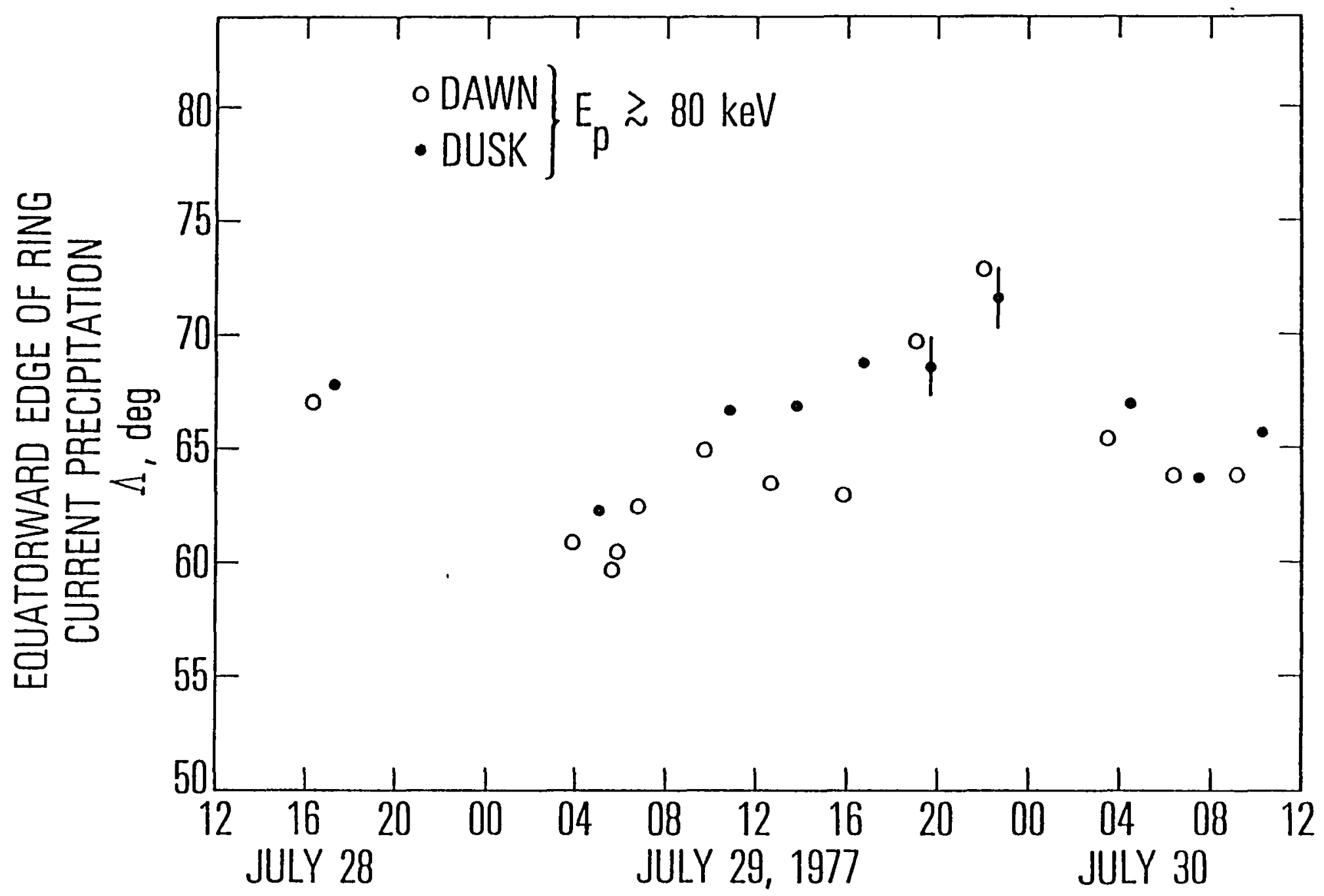

Figure 10(b). Equatorward Edge of Precipitating, Energetic ( $E_{p}>80 \mathrm{keV}$ ) Ring Current Ions from the Aerospace Proton Telescope. 


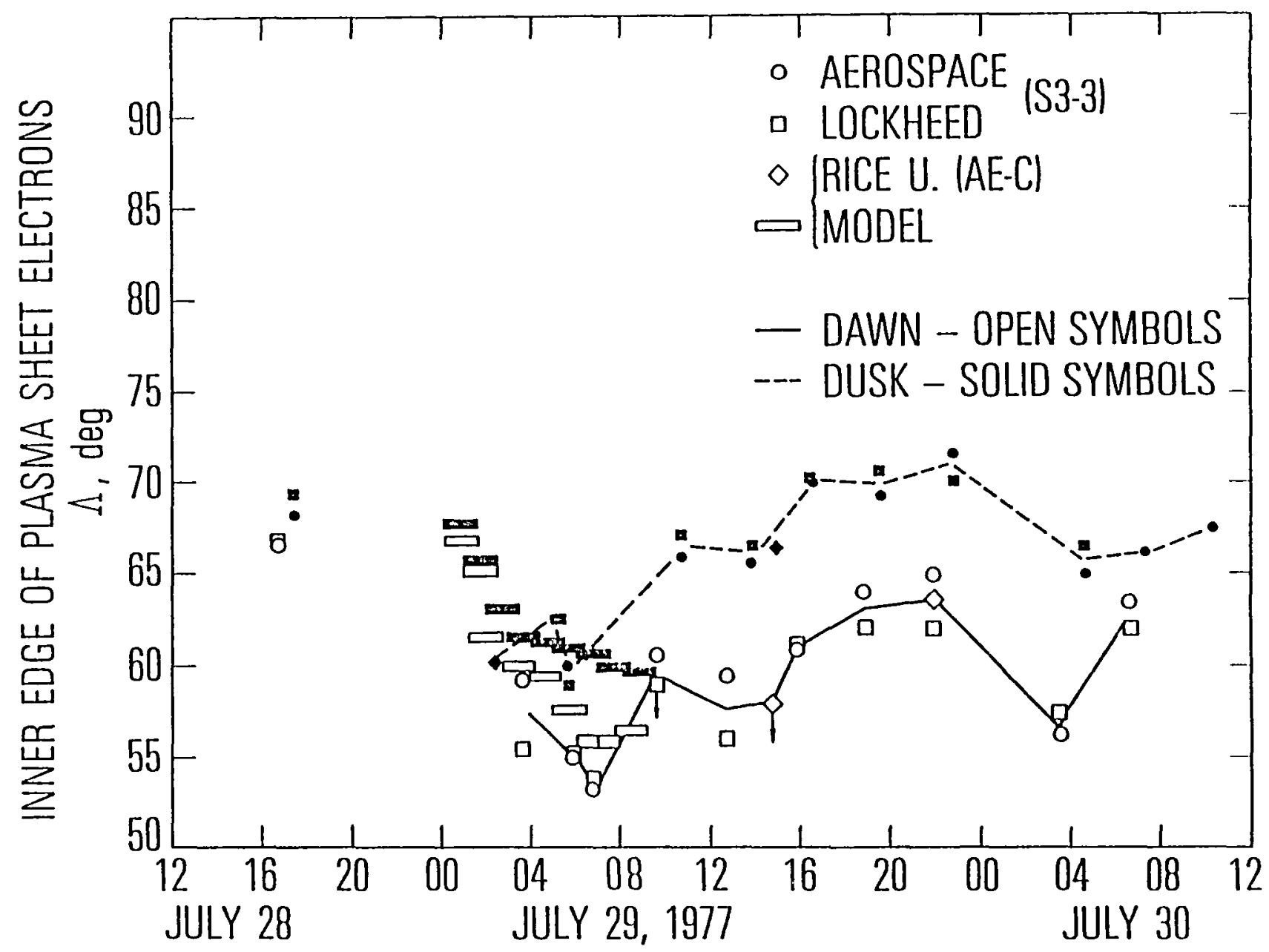

Figure 11. Inner Edge of the Plasmasheet Electrons at Low Altitude. The circles and squares are positions determined using the Aerospace and Lockheed energetic electron measurements. The diamonds are the positions determined by $A E-C$ data ( $P$. Reiff, private communication 1979). The rectangles represent preliminary boundary estimates from a substorm model of this day ( $M$. Harel, private communication and Wolf et a1.,1981). See text. 
dary. Such asymmetries are predicted by simple convection models such as that of Kivelson and Southwood (1975). The asymmetry is nearly constant at $\Delta \Lambda \sim 5-10^{\circ}$ from $\sim 0800$ UT on July 29 to 0600 UT on July 30 . It is seen that, as with the polar cap boundary, the inner edge of the plasma sheet moved poleward during the poststorm recovery from 1600-2400 UT and in fact moved rather far poleward in the dusk sector.

For comparison we show in Fig. 11 the position of this boundary as predicted by a time dependent magnetospheric convection model (Wolf et al., 1981); first at equilibrium (bar points near 0000 UT on July 29) just at the solar wind shock arrival at 0027 UT on July 29, and at 1 hour intervals up to 0830 . The pre and poststorm predictions agree relatively well w1th the observed position of the inner edge of the plasma sheet electrons. The post storm predicted positions show a dawn dusk asymetry similar to the measured data. In fact, it was possible to obtain a good match with the asymmetry of the boundary up to 0630 to 0730 UT (see also Wolf et al., 1981).

The inner edge of the plasma sheet was also observed near the equatorial plane by ATS- 6 just before $0400 \mathrm{UT}$. Its equatorial crossing was thus at 6.6 Re near dusk local time. Since a dipolar mapping from $62^{\circ}$ latitude (F1g. 10b) would place this boundary at $4.5 \mathrm{Re}$, this indicates the field lines were significantly stretched near the equator by the presence of the ring current. This behavior is found in models of the stormtume field (Olsen and Pfitzer, 1981) and has been observed in the dawn sector by Moore et al. (1980) 
Discussion

Pulling together all the in-situ plasma observations for this perıod, as we have done here, allows us to characterzze magnetospheric conditions fairly we11. As was seen in Figure 1 this is a moderately large magnetic storn with several substorms (Manka et al., 1981). The most dramatic effect in the magnetospnere's equatorial region the compression of the magnetopause down to altitudes below $\sim 7$ Re (Ref. Figure 2) on the noon side and possibly close to 6.6 Re near $15 \mathrm{kIT}$. This was shown by the solar wind 1on composition seen by GEOS-1 Erom 0027 UT to at least 0149 UT (Geiss et al., 1978). The ATS-6 synchronous satellite plasma measurements show that boundary layer fluxes were observed at the synchronous altitude at the time of the magnetopause compression. Such fluxes are usually found just inside the magnetopause boundary and would indicate that the boundary is relatively close to ATS-6.

The synchronous altitude observations of the flux increase-decrease events can be understood as resulting from plasma sheet thinning and recovery during the course of a substorm. In this context a satellite such as ATS-6 located near late local evening or midnight may briefly exit from the central plasma sheet into the boundary layer or tail lobes where the energetic particle flux is much lower. During such an occurrence the satellite may also be on auroral field lines at times and observe field aligned ion fluxes accelerated up the field lines from the lonosphere (Sharp et al., 1979; Gorney et al., 1981).

The composition data (Ref. Figure 9) clearly shows that the dommant species outside, and just inside at times, the plasmasphere below $\mathrm{L} \sim 5$ is $0^{+}$ during the disturbed periods. This was true for the equatorial and low- 
altrtude regions. The data also show (Ref. Figures 7, 8 and 9b) that the heavy energetic ions penetrated to altitudes below the plasmapause as defined by the $100 \mathrm{~cm}^{-3}$ level in cold plasma density. In at least one case (Ref. Figure 7 near 0630 UT) the Berkeley electric field data places the corotation boundary well inside the plasmapause boundary as defined by the ion density measurement on S3-3. The flows in the outer morningside plasmasphere were strongly sunward and $\sim 2$ times the corotation velocity. The fon plasma sheet inner edge is in good agreement with the corotation boundary at this time. The occurrance of the energetic ionospheric ions at altitudes below the plasmapause most probably resulted from convection of these energetic ions very deep into the magnetosphere during an increase in the cross-magnetosphere electric field (see Cowley and Ashour-Abdalla, 1976; Kivelson et al., 1980 and references therein). The ions were subsequently left on low drift shells when the electric field decreased and the plasmasphere started to reform at higher altitudes. It is possible that at the time of the measurements the outer plasmasphere is not effectively shielded from the cross-magnetospheric electric fleld.

In most of the cases, the inner edge of the low energy $(<30 \mathrm{keV})$ plasma sheet lons were found to match well the lower boundary of the plasmapause (ref. Figure 7). This may reflect the fact that these ions are expected to experience strong losses at the plasmapause itself (Kennel, 1969; Cornwall et al., 1970; Cornwall et al., 1971).

While there are differences between the dawn and dusk plasmapause positions there is no apparent systematic relationship. The poor temporal resolution of these measurements may have masked such features, although the inner edge of the electron plasma sheet does show the expected systematic local time differences (see Fig. 11). 
Comparison of the inner edge of the energetic (> $80 \mathrm{keV}$ ) ring current proton precipitation (Figure 10a) with the upper limlt of the plasmapause boundary (Figure 7) gave good agreement with previous determinations (MIzera, 1974). We find that although intense fluxes of lons penetrate down to and Inside the plasmapause they are not in strong pitch angle scattering except above the latitudes shown in Figure 10b.

All the boundaries are seen to respond to the activity in a simlar manner. The boundaries decrease in latitude ( $L$ shell) in response to the shock and substorms early in the day and then increase to relatively high values as the magnetosphere quieted late in the day. The most dramatic changes occurred in the polar cap and ring current precipltation boundaries (Figures 5 and 10b). Auroral-like activity is seen to latitudes as high as $\Lambda \sim 85.7^{\circ}$ near local midnight. This indicates that the polar cap may have receded and become very small in area. Such an effect could occur if the interplanetary field turned strongly northward for an extended period and/or the plasma pressure on the magnetopause became much reduced, then the magnetosphere might inflate, reducing the polar cap to a small or negligible area. In fact, King et al. (1981) reported that the interplanetary field did turn northward, the plasma density dropped and the temperature declined after $~ 1400$ UT. We leave further discussions of this high-latitude phenomenon to a companion paper in this 1ssue (Zanettr et al., 1981).

Finally, the combined plasma observations for this day can be summarized as follows.

1. The magnetopause was observed to cross the orbit of the GEOS-1 spacecraft to a distance of 6.6 to $7 \mathrm{R}_{e}$ at the time of the arrival of the solar wind shock front ( 0027 UT). 
2. The polar cap, plasma sheet and plasmasphere boundaries moved inward in response to the substorm activity early on July 29.

3. The suprathermal plasma in the "trough" region of the magnetosphere (poleward of the plasmapause) was dominated by oxygen.

4. The polar cap boundary moved to extremely high latitudes during the afternoon recovery period.

5. The inner edge of the plasma sheet also recovered to higher latitudes during the afternoon quiet period.

6. Comparison of the plasma sheet inner edge at low altitudes with a prediction from a convection model showed they agreed well for the early time on July 29. Comparison with geosynchronous data showed that the dusk field lines were signficantly stretched by the ring current.

7. The position of the plasmapause boundary at $53-3$ altitudes as defined using the ion density and energetic lons were found to be in relatively good agreement .

8. The energetic ion component was observed inside the plasmasphere in a few cases, in the manner of the 'nose' events of Smith and Hoffman (1974). 9. The outer plaswasphere, in at least one case, had sunward morningside flow velocities significantly greater than expected corotation velocities. A similar case occurred on the evening side.

10. The geosynchronous altitudes showed effects related to plasma sheet thinning near times of substorns. 


\section{References}

Baker, D. N., T. A. Frıtz, B. Wilken, P. R. Higbıe, S. M. Kaye, M. G. Kivelson, T. E. Moore, W. Studemann, A. J. Llasley, P. H. SmIth and A. L. Vampola, Observation and Modelıng of Energetic Particles at Synchronous Orbit, J. Geophys. Res., in press, 1981.

Burke, W. J., D. A. Hardy, F. J. Rich, M. C. Kelley, M. Smiddy, B. Shuman, R. C. Sagalyn, R. P. VanCour, P. J. Wildman and S. T. Lai, Electrodynamic Structure of the Late Evening Sector of the Auroral Zone, J. Geophys. Res., $85,1179,1980$.

Cornwall, J. M., F. V. Coroniti and R. M. Thorne, Turbulent Loss of Ring Current Protons, J. Geophys. Res., 75, 4699, 1970.

Cornwall, J. M., H. H. Hilton and P. F. Lizera, Observations of Precipitating Protons in the Energy Range $2.5 \mathrm{keV} \leq E \leq 200 \mathrm{keV}$, J. Geophys. Res., 76, 5220,1971

Cowley, S. W. H. and M. Ashour-Adballa, Adiabatic Plasma Convection in a Dipole Field: Proton Forbidden-Zone Effects for a Simple Electric Field llodel, Planet. Space Sc1, $24,821,1976$.

Decreau, P. M. E., J. Etcheto, K. Knott, A. Pedersen, G. L. Wrenn and D. T. Young, Multi-Experlment Determination of Plasma Density and Temperature, Space Sci. Rev., 22, 633, 1978.

Etcheto, J. and J. J. Bloch, Plasma Density Measurements from the GEOS-1 Relaxation Sounder, Sp. Sc1. Rev., 22, 597, 1978.

Evans, L. C., and E. C. Stone, Access of Solar Protons into the Polar Cap: A Persistent North-South Asymetry, J. Geophys. Res., 74, 5127, 1969.

Fennell, J. F., Access of Solar Protons to the Earth's Polar Caps, J. Geophys. $\underline{\text { Res.., }}$ 78, 1036,1973 . 
Fennell, J. F., D. R. Croley, Jr. and S. M. Kaye, Low-Energy Ion Pitch-Angle Distributions in the Outer Magnetosphere: Ion Zipper Events, J. Geophys. $\underline{\text { Res. }, ~ 86, ~ 3375, ~} 1981$.

Fennell, J.F., P. F. Mizera and D. R. Croley, Jr., Observations of Ion and Electron Distributions During the July 29 and July 30, 1977 Storm Period, Proceedings of Mggnetospheric Boundary Layers Conference, Alpbach, 11-15 June 1979, ESA SP-148, August 1979.

Gelss, J., H. Balsıger, P. Eberhardt, H. P. Walker, L. Weber and D. T. Young, Dynamics of Magnetospheric Ion Composition as Observed by the GEOS Mass Spectrometer, Space Sci. Rev., 22, 537, 1978.

Gorney, D. J., A. Clarke, D. R. Croley, Jr., J. F. Fenne11, J. H. Luhmann and P. F. Mizera, The Distribution of Ion Beams and Conics Below $8000 \mathrm{~km}$, to be published, J. Geophys. Res., 1981.

Johnson, J.F.E., J. J. Sojka and G. L. Wrenn, Thermal/Suprathermal Plasmas Observed by the S-302 Experiment on GEOS-1, Sp. Sci. Rev., 22, 567, 1978. Johnson, R. G., Energetic Ion Composition in the Earth's Magnetosphere, Reviews of Geophys. and Space Phys., 17, 696, 1979.

Kaye, S. M., R. G. Johnson, R. D. Sharp and E. G. Shelley, Observations of Transient $\mathrm{H}^{+}$and $\mathrm{O}^{+}$Bursts in the Equatorial Magnetosphere, to be published, J. Geophys. Res., 1980.

Kaye, S. M., E. G. Shelley, R. D. Sharp and R. G. Johnson, Ion Composition of Zipper Events, J. Geophys. Res., 86, 3383, 1981 .

Kennel, C. F., Consequences of a Nagnetospherıc Plasma, Rev. Geophys., 7, 379, 1969.

Klng, J. E., R. P. Lepping and J. D. Sullivan, On the Complex State of the Interplanetary Medium of July 29, 1977, J. Geophys. Res., this issue, 1981. 
Kivelson, M. G., S. I. Kaye and D. J. S outhwood, The Physics of Plasma Injection Events, in Dynamics of the Magnetosphere, S. I. Akasofu, ed., 385, D. Reidel Pub., Dordrecht, Netherlands, 1980.

Kivelson, M. G. and D. J. Southwood, Local Time Variations of Particle Flux Produced by an Electrostatic Field in the Magnetosphere, J. Geophys. Res., 80, 56, 1975 .

Knott, K., D. Fairfield, A. Korth and D. Young, Observations Near the Magnetopause at the Onset of the July 29, 1977 Sudden Storm Commencement, J. Geophys. Res., this 1ssue, 1981 .

Lundin, R., L. R. Lyons and N. Pissarenko, Observations of the Ring Current Composition at $\mathrm{L} \leq 4$, Geophys. Res. Lett., 7, 425, 1980 .

Lyons, L. R. and D. S. Evans, The Inconsistency Between Proton Charge Exchange and the Observed Ring Current Decay, J. Geophys. Res., 81, 6197, 1967. Manka, R. H., T. A. Fritz, R. G. Johnson, M. J. Teague, J. I. Vette and R. A. Wolf, Overview of the July 2y, 1977 Substom Event, to be published, J. Geophys. Res., this issue, 1981 .

McDiarmid, I. B., J. R. Burrows and M. D. Wilson, Solar Particles and the Daysıde Limit of Closed Field Lines, J. Geophys. Res., 77, 1103, 1972 .

Meng, C. -I., Polar Cap Variatıons and the Interplanetary Magnetic Fleld, in Dynamics of the Magnetosphere, S. -I. Akasofu, ed., D. Reidel Publ., Dordrecht, Holland, 1979.

Meng, C. -I. and H. W. Kroehl, Intense Uniform Precipitation of Low-Energy Electrons Over the Polar Cap, J. Geophys. Res., 82, 2305, 1977. Mizera, P. F., Observations of Precipitating Protons With Ring Current Energies, J. Geophys. Res., 79, 581, 1974.

Mzzera, P. F. and J.F. Fennell, Satellite Observations of Polar, ilagnetotail Lobe, and Interplanetary Electrons at Low Energies, Review of Geophys. and Sp. Phys., 16, 147, 1978 . 
Ulzera, P. F. and J.F. Fennell, Signatures of Electric Fields from High and Low Altitude Particle Distrıbutions, Geophys. Res. Lett., 4, 311, 1977 . ilizera, P. F., J. F. Fennell, F. S. Nozer, R. B. Torbert, M. Temerin, R. Lysak, M. K. Hudson, C. A. Cattell, R. G. Johnson, R. D. Sharp, A. Ghielnetti and P. M. Kintner, The Aurora Inferred from S3-3 Particles and Fields, J. Geophys. Res., 86, 2329, 1981 .

Moore, T. E., R. L. Arnoldy, B. Hultquist and B. Aparicio, The Dawn Polar Cap Boundary at High Altitude, Planet. Sp. Sci., 28, 1019, 1980.

Mozer, F. S. and R. B. Torbert, An Average Parallel Electric Field Deduced from the Latitude and Altitude Variations of the Perpendicular Electric Field Below 8000 Kilometers, Geophys. Res. Lett., 3, 219, 1980.

ilozer, F. S., C. A. Cattell, M. K. Hudson, R. L. Lysak, R. B. Torbert and M. Temerin, Satellite Heasurements and Theories of Low-Altitude Auroral Particle Acceleration, Space Sci. Rev., 27, 155, 1980.

Olsen, W. P. and K. A. Pfitzer, A Dynamic Model of the Magnetospheric Magnetic and Electric Fields for July 29, 1979, J. Geophys. Res., this issue, 1981 .

Pedersen, A., R. Grard, K. Knott, D. Jones and A. Gonfalone, Measurements of Quasi-Static Electric Flelds Between 3 and 7 Earth Radif on GEOS-1, Space Sci. Rev., 22, 33, 1978.

Richardson, J. D., J.F. Fennell and D. R. Croley, Jr., Observations of Field Aligned Ion and Electron Beams from SCATHA (P78-2), J. Geophys. Res., in press, 1981 .

Sharp, R. D., R. G. Johnson, and E. G. Shelley, Energetic Particle Measurements from Within Ionospheric Structures Responsible for Auroral Acceleration Processes, J. Geophys. Res., 84, 480, 1979. 
Torbert, R. B., C. A. Cattell, F. S. Mozer and C. -I. Meng, On the Identification of the Polar Cap, Geophys. Res. Lett., submitted, 1981.

Wildman, P. J. L., A Low Energy Ion Sensor for Space lleasurements With Reduced Photo Sensitivicy, Space Sci. Inst., 3 , 363, 1977 .

Wilken, B., D. N. Baker, P. R. Higbie, T. A. Fritz, The Energetıc Particle Response to the Magnetospheric Impulse Caused by the Interplanetary Shock on July 29, 1977, J. Geophys. Res., this issue, 1981.

Wilken, B., T. A. Fritz, A. Korth and G. Kremser, Substorm-Associated Injections of Energetic Ions Observed by GEOS-1 and ATS- 6 in and Near Synchronous Altitude, Space Sci. Rev., 22, 647, 1978.

Winningham, J. D. and W. J. Heikkfla, Polar Cap Auroral Electron Fluxes Observed with Isis 1, J. Geophys. Res., 79, 949, 1974.

Wolf, R. A., M. Harel, R. W. Spiro, G. -H. Voigt, P. H. Reiff and C. -K. Chen, Computer Simulation of Inner Magnetospheric Dynamics for the Magnetic Storm of July 29, 1977, J. Geophys. Res., this issue, 1981.

Zanettı, L. J., T. A. Potemra, S. I. Akasofu, J. H. Allen, W. Baumjohann, C. A. Cattell, J. F. Fennell, R. H. Manka, P. H. Reiff, R. B. Torbert and J. K. Walker, Auroral Zone Variations on July 29, 1977, J. Geophys. Res., this 1ssue, 1981 .

Vampola, A. L., Access of Solar Electrons to Closed Field Lines, J. Geophys. Res., 76, 36, 1971 . 


\section{End of Document}

